\title{
Synthesis, structure and function of $\pi$-stacked polymers
}

\author{
Tamaki Nakano
}

\begin{abstract}
Macromolecular conformation often has a significant effect on the properties of polymeric materials, and hence, conformational control in synthesizing a polymer is an important goal in polymer science. As a new conformational motif of vinyl polymers having side-chain $\pi$-electronic groups, we have introduced a ' $\pi$-stacked structure' in which side-chain chromophores are regularly stacked on top of each other and main-chain $\mathrm{C}-\mathrm{C}$ bonds have a nearly all-trans, zigzag conformation. $\pi$-Stacked polymers can be prepared by vinyl polymerization of dibenzofulvene (DBF) and its derivatives. On the basis of the controlled structure, poly(DBF) and its derivatives exhibit unique photophysical and electronic properties as vinyl polymers. In addition, introduction of chirality to $\pi$-stacked polymers was also achieved. In this review, the synthesis of poly(DBF) and its derivatives and their structural analyses and properties are described.
\end{abstract}

Polymer Journal (2010) 42, 103-123; doi:10.1038/pj.2009.332

Keywords: charge transport; chirality; dibenzofulvene; helix; photophysical properties; $\pi$-stacked structure

In designing functional organic materials with desired properties, spatial arrangement control of constituent molecules is an important factor because molecules in a regulated assembly often indicate properties different from those in solution or in gas phase because of specific intermolecular interactions. Effective molecular assembly control can be achieved by arrangement of functional molecules as a part of a polymer chain with a regulated conformation and configuration in which the polymer backbone functions as a structural template or scaffold. This is possible either by polymerizing functional molecules as monomers or by attaching functional molecules through a chemical reaction to a polymer chain. In the former case, the functional molecules to be aligned need to have a polymerizable moiety such as a vinyl group; they are a part of monomers and become constituents of a polymer chain as a part of monomeric units, typically as side-chain groups. The monomer structure itself may significantly contribute to the formation of a regulated polymer chain structure through intermolecular repulsion or attraction. An advantage of these polymer-based methods over other methodologies developed mainly for low-molecular-weight compounds based on the accumulation of relatively weak forces is that molecular orders formed along a polymer chain are generally stable due to covalent bonds. Moreover, using a polymer chain, a very tight or close packing of molecules (monomeric units), which is not plausible for the method based on weak intermolecular attractions, is possible when the enthalpy gain in covalent bond formation by polymerization or by polymer reaction outweighs the loss in free energy in packing molecules tightly into a small space around the polymer chain.
Although these polymer-based methods generally require more synthetic efforts than intermolecular-force-based methods, a wider variety of molecular orders may be possible on the basis of recent advances in polymerization chemistry, which have realized various macromolecular architectures.

Molecules can assemble in various ways. Among them, a relatively simple order known for aromatic molecules is a $\pi$-stacked assembly in which planar aromatic molecules align closely in a parallel, cofacial manner. $\pi$-Stacked molecules and assembly often show characteristic physical properties such as reduced photoabsorption intensity (hypochromism, hypochromic effect), excimer or exciplex formation on photoexcitation, and charge transport. The last property has practical importance and has been demonstrated for organic molecules and metallic complexes, such as the conducting tetrathiafulvalene-7,7,8,8,tetracyanoquinodimethane complex in which tetrathiafulvalene and 7,7,8,8,-tetracyanoquinodimethane form independent columnar stacks ${ }^{1}$ and the tetramethyltetraselenafulvaene- $\mathrm{PF}_{6}$ complex in which tetramethyltetraselenafulvaene molecules are in a stacked arrangement. ${ }^{2}$ In either case, the stacked molecules have an important role in effectively transporting a hole or an electron.

Although the molecular stacks of tetrathiafulvalene-7,7,8,8,-tetracyanoquinodimethane and tetramethyltetraselenafulvaene- $\mathrm{PF}_{6}$ complexes were achieved in crystal, a $\pi$-stacked structure has also been constructed using polymer chains. Stable and regulated $\pi$-stacked structures in polymers have been realized for DNAs, ${ }^{3}$ oligo $(m$-phenyleneethynylene)s, ${ }^{4}$ oligomers consisting of alternating donor and acceptor monomeric units, ${ }^{5,6}$ oligomers consisting of acceptor 
monomeric units in the main chain that interact with a low-molecular-weight donor molecule, ${ }^{7}$ oligomers having perylene moieties in the main chain, ${ }^{8,9}$ polymers consisting of cyclophane units, ${ }^{10-12}$ a polymer of bezofulvene derivative, ${ }^{13,14}$ and polymers of dibenzofulvene $(\mathrm{DBF})$ and its derivatives (Chart 1$).{ }^{15-22}$ In a DNA duplex, paired bases are regularly stacked inside the helical strand. In oligo
( $m$-phenyleneethynylene)s, phenylene groups in the main chain closely overlap because of helical folding of the polymer chain. In oligomers consisting of alternating aromatic donor and acceptor units and those consisting of acceptor units interacting with added donor molecules, the chain folds into a pleated conformation because of a donor-acceptor interaction. In paracyclophane polymers,<smiles>CC#Cc1cc(C(=O)OCCOC)cc(C(C)(C)C)c1</smiles>

Oligo(m-phenyleneethynylene)<smiles>CC(=O)NC(CNCCCOc1cccc2c(OCCCC(=O)N[C@@H](CC(=O)[O-])C(=O)NCCN3C(=O)c4ccc5c6c(ccc(c46)C3=O)C(=O)N(CCC(=O)O)C5=O)cccc12)CC(=O)O</smiles>

Donor-acceptor oligomer

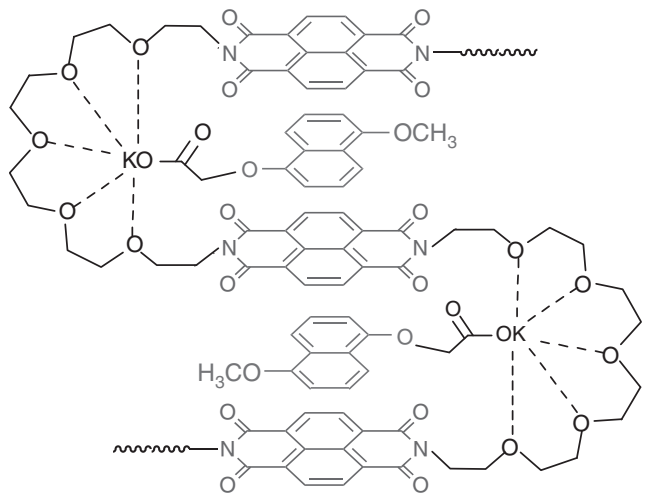

Acceptor oligomer interacting with donor

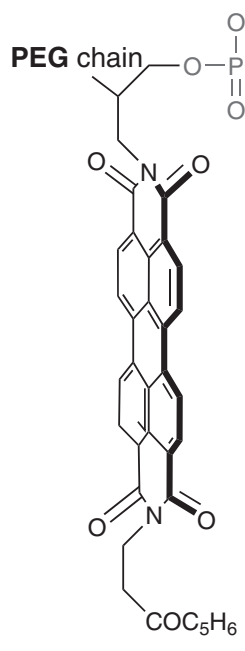

$\mathrm{OCH}_{2} \mathrm{CH}_{2} \mathrm{CN}$

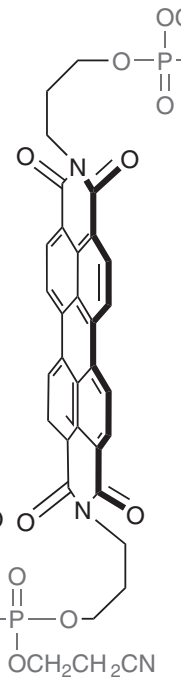

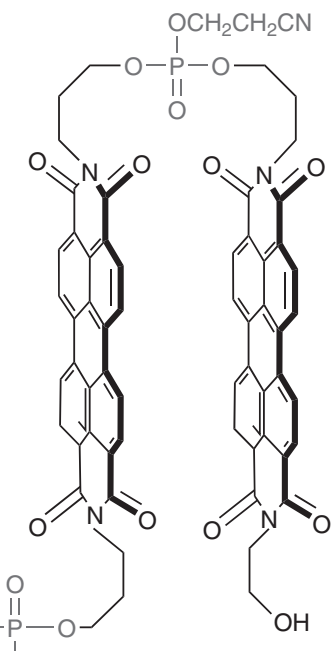

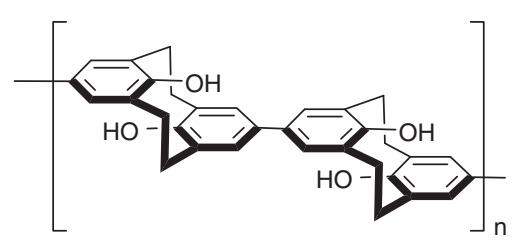

Polymer containing cyclophane units<smiles>CCOC(=O)C1=C(c2ccc(C)cc2)c2ccccc2C1(C)C</smiles>

Benzofulvene polymer

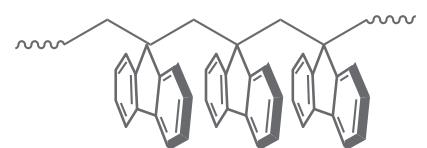

Poly(DBF)

Chart 1 Synthetic $\pi$-stacked polymers. 
cofacially stacked two benzene rings form a monomeric unit. In poly(DBF), the side-chain aromatic groups are tightly stacked on top of each other along the almost all-trans main chain.

In addition, in close connection to $\pi$-stacked polymers, $\pi$-layered polymers, in which various aromatic groups are layered in a regular manner in a polymer chain with the aid of scaffold units fixing the orientation of the aromatic groups, have been reported. ${ }^{23,24}$

Among the examples of $\pi$-stacked polymers, poly(DBF) and its derivatives are unique in the fact that they are vinyl polymers and can be synthesized using versatile vinyl polymerization techniques. It should be noted here that oligo(DBF) has also been synthesized not by vinyl polymerization but by a completely organic synthetic method. ${ }^{25}$ Poly(DBF)'s closest structural kin in vinyl polymers is perhaps polystyrene. However, poly(DBF) and its derivatives have characteristic structural and functional features that are not known for polystyrene and its analogs. Herein, the synthesis, structure, and function of $\pi$-stacked poly(DBF) and its derivatives are described.

\section{POLYMERIZATION OF DBF}

Dibenzofulvene, the monomer, can be readily synthesized from 9-hydroxymethylfluorene by reaction in a methanol solution containing $\mathrm{KOH}^{26,27}$ and purified by recrystallization from hexane. Polymerization of this compound was first reported in 1937; however, no details of the reaction or the structure of the products have been described. ${ }^{28}$

The structure of DBF is closely related to that of 1,1-diphenylethylene (DPE), which is known as a representative vinyl compound that does not produce a homopolymer through any kind of catalysis. DPE's low reactivity has been ascribed to steric reasons. ${ }^{29-32} \mathrm{DBF}$ differs from DPE only in the fact that the two phenyl groups are connected to each other to form a fused ring structure. However, DBF readily affords a polymer by anionic, radical and cationic catalyses (Figure 1).

To obtain information on why DBF yields a polymer, whereas DPE does not, the electron density of the vinyl group was first considered. The ${ }^{13} \mathrm{C}$ chemical shift of the $\beta$-vinyl carbon of DBF was 107.7 p.p.m., whereas those of DPE and styrene were 114.3 and 113.6p.p.m., respectively, as determined in $\mathrm{CDCl}_{3}$ at $23^{\circ} \mathrm{C}$, suggesting that the $\beta$-carbon of DBF has a higher electron density compared with that of DPE and styrene. This was supported by the Mulliken charges obtained for DBF, DPE and styrene by ab initio calculations (HF// MP2/6-31G* and HF//MP2/6-31G**) (Table 1). The monomer structures were optimized by PM5 calculation ${ }^{33}$ before the $a b$ initio analysis. The results are consistent with the finding that the $\beta$-carbon of DBF has a higher electron density. However, these results only support the reactivity of DBF during cationic polymerization.

Next, the structure of DBF was examined using semiempirical molecular orbital calculations. The AM1 calculation ${ }^{33}$ afforded a nearly planar structure for DBF, which is not possible for DPE (Figure 2). The nearly planar structure should not only reduce steric hindrance but also effectively stabilize the anionic, cationic or radical species at the $\alpha$-carbon through electron conjugation. In addition, the bond angle between the two vinyl-to-phenyl bonds in DBF was $105.6^{\circ}$, which is significantly deviated from $120^{\circ}$, implying that the vinyl group of DBF contains significant strain energy. This was supported by the calculations of the heat of formation $\left(\mathrm{H}_{\mathrm{f}}\right)$ of DBF and 9-methylfluorene by the PM5 method: $\mathrm{H}_{\mathrm{f}}$ of DBF was $68.6 \mathrm{kcal} \mathrm{mol}^{-1}$, whereas that of 9 -methylfluorene was $40.9 \mathrm{kcal} \mathrm{mol}^{-1}$. Therefore, strain relief may be a driving force of DBF polymerization, regardless of the type of active species. This would reasonably explain the fact that DBF polymerizes even with $t$-BuOK as described later. The enhanced reactivity of cyclic monomers having an exomethylene group compared with the acyclic parent vinyl compound has been pointed out; ${ }^{34-37}$ however, the acyclic counterparts do slowly produce homopolymers in the examples in references. ${ }^{34-37}$ whereas DPE does not produce a homopolymer.

In the anionic polymerization of DBF, the reactions using $n$-butyllithium ( $n$-BuLi) and 9-fluorenyllithium (FlLi) led to a nearly complete monomer consumption at $-78^{\circ} \mathrm{C}$, whereas that using a Grignard reagent $\left(\mathrm{CH}_{3} \mathrm{MgBr}\right)$ required room temperature to achieve a reasonable monomer conversion (Figure 3a). It is interesting that $t$-BuOK, a weak nucleophile, very effectively polymerized DBF at $-78^{\circ} \mathrm{C}$ (Figure $3 \mathrm{~b}$ ). In this case, a 9-fluorenyl anion, a carbanion, is generated from the oxy anion $\left(t-\mathrm{BuO}^{-}\right)$by reaction with $\mathrm{DBF}$. Although the generation of a carbanion from an oxy anion has been accomplished using Si-containing cyclic compounds, the method

Table 1 Mulliken charges of vinyl group of dibenzofulvene (DBF), 1,1-diphenylethylene (DPE) and styrene ${ }^{a}$

\begin{tabular}{|c|c|c|c|c|c|c|}
\hline \multirow[b]{2}{*}{ Basis set } & \multicolumn{2}{|c|}{$D B F$} & \multicolumn{2}{|c|}{$D P E$} & \multicolumn{2}{|c|}{ Styrene } \\
\hline & $\alpha$-Carbon & $\beta$-Carbon & $\alpha$-Carbon & $\beta$-Carbon & $\alpha$-Carbon & $\beta$-Carbon \\
\hline $6-31 G^{*}$ & 0.154 & -0.463 & 0.057 & -0.423 & -0.138 & -0.416 \\
\hline $6-31 G * *$ & 0.121 & -0.326 & 0.036 & -0.298 & -0.084 & -0.300 \\
\hline
\end{tabular}

aEstimated by ab initio calculations (HF//MP2/6-31G*, HF//MP2/6-31G**) for PM3-optimized structures.
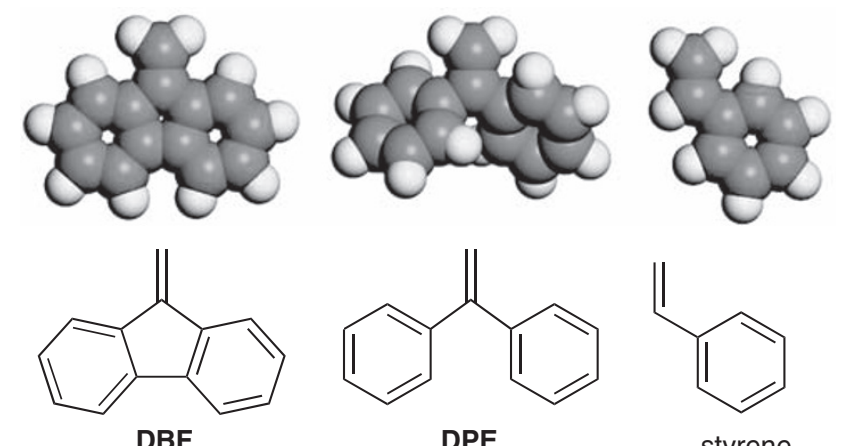

styrene

Figure 2 Optimized structures of DBF, DPE and styrene (AM1).

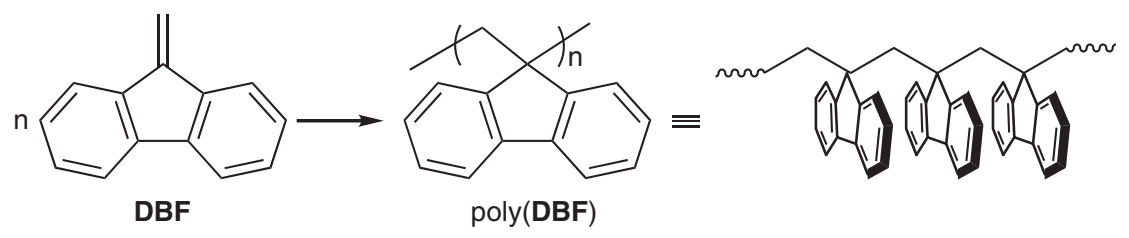

Figure 1 Polymerization of DBF. 


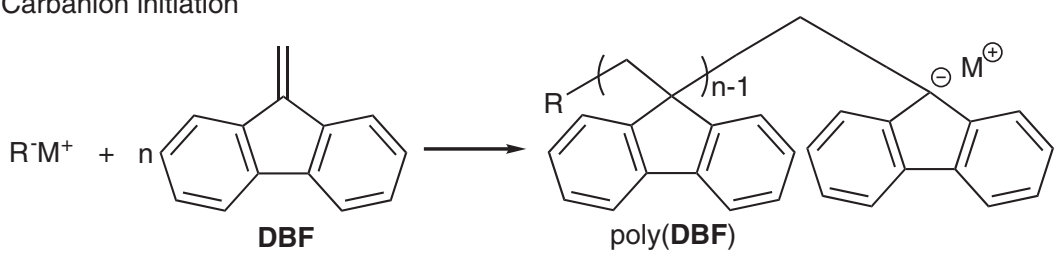

$\mathrm{R}^{-} \mathrm{M}^{+}=$organolithiums, Grignard reagents

b tBuOK initiation

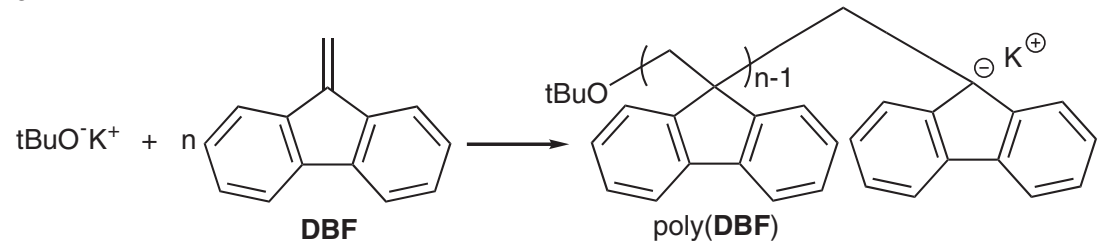

Figure 3 Anionic polymerization of DBF with carbanions (a) and $t$-BuOK (b).

using a hydrocarbon compound is only possible with DBF so far. ${ }^{38,39}$ The anionic methods were used to synthesize uniform oligomers of DBF having completely controlled chemical and stereochemical structures used for the detailed structure analyses.

The radical polymerization of DBF has also been studied in detail. ${ }^{17}$ Radical polymerization products have been found to have virtually the same chemical structure as that of anionic polymerization products. The conformation specificity (stereospecificity) of DBF radical polymerization was also similar to that of anionic polymerization. However, radical polymerization products seemed to have a very small amount of irregular, defective conformation incorporated into the mostly $\pi$-stacked chain. Conformation specificity was affected by the initial monomer concentration and reaction temperature. This observation was explained by a proposed mechanism in which two types of growing radicals having different conformations and different conformation specificities mediate polymerization.

Owing to its high reactivity, DBF reacts even with oxygen contained in the air in the solid state and affords a copolymer consisting of DBF and -O-O- units (Figure 4). ${ }^{17}$ This polymerization is assumed to be mediated by radical growing species. On standing in a flask under air or pure $\mathrm{O}_{2}$ atmosphere, DBF crystals produce a polymer. The monomer crystals became slightly yellow during the reaction, but there was no change in the apparent state of the solid material, indicating that the reaction took place in the solid state. The molecular weight of the polymer significantly decreased in a heat treatment at $100-175^{\circ} \mathrm{C}$, probably because thermal scission of the -OO- bonding takes place on heating. The ambient light seems to have little effect on the polymerization behavior. This is in contrast to the fact that sunlight or ultraviolet irradiation is necessary for the octadecyl sorbate- $\mathrm{O}_{2}$ copolymerization system. ${ }^{40}$

Solid-state polymerization is an efficient method for controlling the polymer structure. Several diyne and diene monomers undergo solidstate polymerization, leading to polymers with controlled chemical and stereostructures. ${ }^{41-47}$ However, there has been no clear examples of solid-state polymerization of vinyl monomers, except for the reactions using solid matrices (inclusion polymerization) ${ }^{48-52}$ and the DBF polymerization described here. ${ }^{17}$

Although the details are still under investigation, cationic initiators can also effectively polymerize DBF. ${ }^{14}$

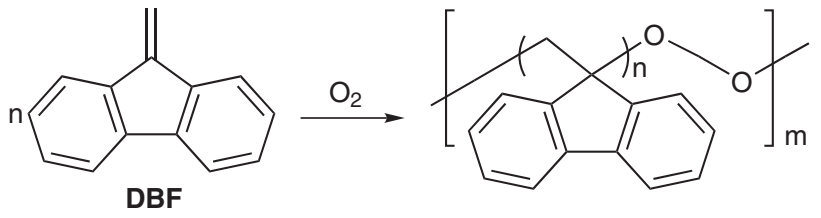

Figure 4 DBF- $\mathrm{O}_{2}$ copolymerization.<smiles>C=C1c2ccccc2-c2ccccc21</smiles>

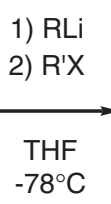

1) $R L i$

2) $R^{\prime} X$

$-78^{\circ} \mathrm{C}$

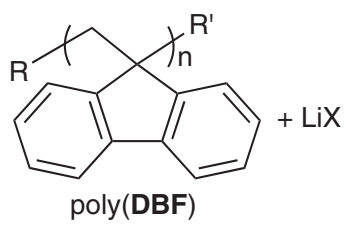

poly(DBF)
Figure 5 Synthesis of poly(DBF)s having different terminal groups by the anionic polymerization technique using various initiators and terminating reagents.

\section{PREPARATION AND ISOLATION OF UNIFORM DBF OLIGOMERS FOR STRUCTURAL ANALYSES}

The $\pi$-stacked structure of poly(DBF) has been firmly established both in the solid-state (crystal) and in solution. ${ }^{15,20}$ Structural analyses were performed using pure oligomers with various terminal groups prepared by anionic polymerization using various initiators and terminators. Oligomers having a uniform degree of polymerization (DP) were isolated by preparative size exclusion chromatography.

Polymerization of DBF was initiated using an organolithium and was terminated using a protonating or an alkylating reagent (Figure 5). The initiators were 9-FlLi, $n$-BuLi, methyllithium and phenyllithium, and the terminating reagents were methanol, ethyl iodide and benzyl bromide $\left(\mathrm{PhCH}_{2} \mathrm{Br}\right)$. The conditions and results of the reactions with the expected polymer structures are summarized in Table 2. In all cases, the DBF monomer was consumed in a high yield.

In some cases, the reaction products were partially insoluble in tetrahydrofuran (THF) or chloroform. The THF-soluble and insoluble parts indicated very similar infrared signals, suggesting that chemical structures of the soluble and insoluble parts are identical. Because polymerization at a higher $(\mathrm{DBF}) /($ initiator) ratio tended to produce a 
Table 2 Anionic polymerization of dibenzofulvene (DBF) in tetrahydrofuran (THF)

\begin{tabular}{|c|c|c|c|c|c|c|c|c|c|}
\hline Entry & Polymer structure ${ }^{a}$ & $\begin{array}{c}D B F \\
(\mathrm{mmol})\end{array}$ & $\begin{array}{l}\text { Initiator } \\
\text { (mmol) }\end{array}$ & $\begin{array}{l}\text { Terminator } \\
(\mathrm{mmol})\end{array}$ & $\begin{array}{l}\text { Temp. } \\
\left({ }^{\circ} \mathrm{C}\right)\end{array}$ & $\begin{array}{l}\text { Time } \\
\text { (hr) }\end{array}$ & $\begin{array}{c}\text { Conv. } \\
(\%)\end{array}$ & $\begin{array}{l}\text { THF-solublec } \\
\text { part yield (\%) }\end{array}$ & $M n^{\mathrm{d}}$ \\
\hline 1 & & 5.6 & $\begin{array}{l}\text { 9-FILi } \\
(1.1)\end{array}$ & $\begin{array}{l}\mathrm{MeOH} \\
(4.0)\end{array}$ & -78 & 24 & $>99$ & $>99$ & 860 \\
\hline 2 & 1 & 4.6 & $\begin{array}{l}\text { 9-FILi } \\
(9.3)\end{array}$ & $\begin{array}{l}\mathrm{MeOH} \\
(12.1)\end{array}$ & 0 & 1 & $>99$ & $>99$ & 350 \\
\hline 3 & & 10.0 & $\begin{array}{l}\text { MeLi } \\
(2.0)\end{array}$ & $\begin{array}{l}\mathrm{CH}_{3} \mathrm{CH}_{2} \mathrm{I} \\
(25.0)\end{array}$ & -78 & 48 & 84 & 98 & 380 \\
\hline 4 & & 11.2 & $\begin{array}{l}n \text {-BuLi } \\
(2.2)\end{array}$ & $\begin{array}{l}\mathrm{MeOH} \\
(6.2)\end{array}$ & -78 & 24 & $>99$ & 81 & 790 \\
\hline 5 & & 2.8 & $\begin{array}{l}n \text {-BuLi } \\
(0.93)\end{array}$ & $\begin{array}{l}\mathrm{PhCH}_{2} \mathrm{Br} \\
(8.4)\end{array}$ & -78 & 24 & $>99$ & 99 & $990^{e}$ \\
\hline 6 & & 10.0 & $\begin{array}{l}\text { PhLi } \\
(2.0)\end{array}$ & $\begin{array}{l}\mathrm{PhCH}_{2} \mathrm{Br} \\
(16.8)\end{array}$ & -78 & 48 & 84 & 63 & 950 \\
\hline
\end{tabular}

${ }^{a} n-1$ and $n$ denote polymerization for entry 1 and 2-5, respectively.

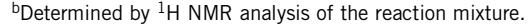

CTHF-sol. part was a mixture of oligomers and unreacted monomer when the monomer conversion was not quantitative. The yield of this part was calculated excluding the weight of the unreacted monomer.

dDetermined by GPC using two OligoPore columns connected in series with oligo(dibenzofulvene (DBF))s as the standard (eluent THF).

eDetermined by GPC using two TSKgel G100OH $\mathrm{HR}_{\mathrm{R}}$ columns connected in series with oligo(DBF)s as the standard (eluent THF). Reproduced with permission from Nakano et al. ${ }^{15}$ Copyright (2003) American Chemical Society.

larger amount of insoluble parts, higher-molecular-weight fractions may tend to become insoluble probably because of crystallinity of the poly(DBF) chain.

The reactions afforded the products (oligomers and polymers) with five terminal-group combinations, 1-5. In the structure of 1,n-1 instead of $n$ has been used to describe the number of monomeric units incorporated into the chain through polymerization (DP) so that $n$ corresponds to the number of fluorene units in a chain. This is because the number of fluorene units in a chain is important in discussing the formation of the $\pi$-stacked conformation of 1 than DP. For 2-5, the number of fluorene units corresponds to DP.

The benefit of introducing terminal groups was confirmed by MALDI-Mass spectrum. The observed mass numbers supported the expected polymer structures. Although unintended protonation of the growing anion with protonic contamination could lead to a polymer having hydrogen at the termination end in entries 3, 5 and 6 in Table 2 aiming at structures 2, 4 and 5, respectively, the corresponding Mass spectra showed no clear peaks based on oligomers having hydrogen at the termination end of the chain.
To obtain detailed information on the $\pi$-stacked conformation of the DBF polymer and its effect on photophysical and electrochemical properties, THF-soluble products were separated into oligomers that are uniform in terms of the number of fluorene units in a chain (1-5 in Table $1 ; n=2-8)$ and polymers $(n \geqslant 9$, mixture) using size exclusion chromatography (Figure 6). The chain lengths of isolated oligomers were determined by MALDI-Mass spectra. Isolated oligomers contained a small amount of higher- and lower-molecular-weight fractions. The purity of oligomers 1 of $n=2-8$ was in the range of $95-99 \%$ and that of oligomers 2 of $n=2-8$ was in the range of $92-99 \%$. The number average molecular weights of polymers 1 and 2 (mixture of $n \geqslant 9)$ were $M_{\mathrm{n}}=1700(n=9.6)$ and $M_{\mathrm{n}}=1890(n=10.4)$, respectively.

\section{SOLID-STATE STRUCTURE OF $\pi$-STACKED POLY(DBF): X-RAY CRYSTAL ANALYSES}

The oligomers isolated by size exclusion chromatography were subjected to crystallization for X-ray crystal structure analysis. ${ }^{15,20}$ Some of the oligomers led to single crystals suitable for X-ray analyses by recrystallization from a chloroform solution. Crystal structures 


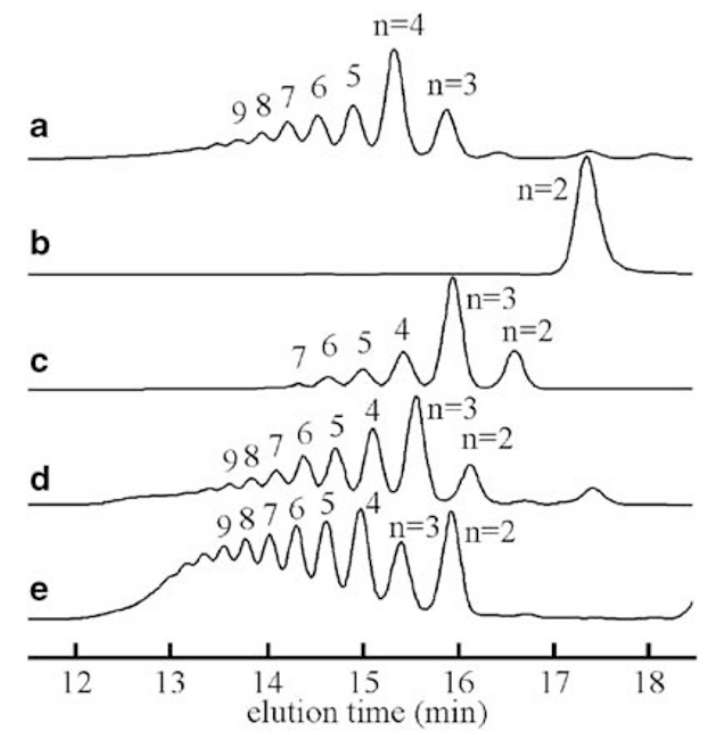

Figure 6 Size exclusion chromatography curves of oligo (DBF)s 1 (Table 2, entry 1) (a), 1 (Table 2, entry 2) (b), 2 (Table 2, entry 3) (c), 3 (Table 2, entry 4) (d), 5 (Table 2, entry 6) (e) (column, two PL OligoPore Columns $(30 \times 0.72$ (i.d.) cm) (Polymer Laboratories, Varian Inc., Palo Alto, CA, USA); eluent, THF; flow rate, $\left.1.0 \mathrm{ml} \mathrm{min}^{-1}\right)$. Reproduced with permission from Nakano et al. ${ }^{15}$ Copyright (2003) American Chemical Society.

were solved for $\mathbf{1}(n=2$ and 4), $\mathbf{2}(n=2$ and 6), $3(n=3), \mathbf{4}(n=4)$ and 5 $(n=2$ and 5$)$. The crystal structures are shown in Figure 7. Single crystal structures indicated two conformational characteristics: (i) the in-chain fluorene moieties of oligomers of $n=4-6$ are in $\pi$-stacked conformation, with the corresponding main-chain carbon-carbon bonds having a slightly twisted all-trans structure regardless of the terminal groups; and (ii) the chain-terminal fluorene moieties are in $\pi$-stacked conformation when the terminal group is ethyl or bulkier, whereas they are flipped when the terminal group is hydrogen. It is also noteworthy that the $\pi$-stacking is not in a perfectly face-to-face manner but the fluorene groups are slightly twisted; the twist takes place in one direction in a $\pi$-stacked structure consisting of three or more fluorene units leading to a helical structure. In addition, the stacked fluorene groups are not completely parallel to each other, which is probably because of steric repulsion. The twisted $\pi$-stacked structure is most clearly confirmed in 2 of $n=6$, the longest molecule for which the crystal structure was solved. This oligomer has a $\pi$-stacked conformation throughout the chain and forms a long-pitched, single-handed helical structure in which ca. nine monomeric units are expected to form one turn as a result of the twisted alignment of the fluorene groups. The conformationally enantiomeric right- and left-handed helices are paired in the solid state, that is, the crystal is formed as a racemic crystal. Induction of single-handed helicity is discussed later in this article.

\section{SOLUTION STRUCTURE OF $\pi$-STACKED POLY(DBF): EXPERIMENTAL ${ }^{1} \mathrm{H}$ NMR ANALYSES}

${ }^{1} \mathrm{H}$ nuclear magnetic resonance (NMR) spectra of oligomers were measured to confirm their chemical structure and to obtain information on the solution conformation of oligomers 1 and $\mathbf{2}(n=2-8)$ and polymers $1\left(M_{\mathrm{n}}=1700, n=9.6\right.$, mixture of $\left.n \geqslant 9\right)$ and $2\left(M_{\mathrm{n}}=1890\right.$, $n=10.4$, mixture of $n \geqslant 9)$. Because poly (DBF) has no stereocenters in the main chain, the chemical shift information of a proton signal should only reflect conformation of the oligomer in its vicinity.

1D spectra are shown in Figures 8 and 9, and the chemical shift values are summarized in Tables 3 and 4 . Peak assignments were performed on the basis of $\mathrm{H}-\mathrm{H}$ correlated spectroscopy (COSY) and nuclear Overhauser enhanced and exchange spectroscopy (NOESY) spectra. The structures of 1 and 2 of $n=8$ with the proton numbering system are shown in Figure 10 as generic specimens. The protons showing COSY correlation peaks are marked by blue arrows and those showing NOESY correlations are marked by red arrows in Figure 10. The same proton-proton correlations were also observed for oligomers of $n=2-7$.

As for oligomers 1, the triplet peaks having an intensity of two protons were first assigned to the terminal methine protons, and the signals due to the methylene protons neighboring the methines were then found by COSY experiment. In the case of oligomers 2 , the triplet peaks in the highest magnetic-field region were assigned to the terminal methyl protons, and the neighboring methylene signals were identified by COSY experiment.

The peak assignments of the remaining main-chain methylene and aromatic protons were determined on the basis of the 1D spectral profiles and the NOESY spectra. In the 1D spectra, all oligomers indicated only one set of terminal peaks: triplet methine signals for $\mathbf{1}$ and ethyl signals consisting of a methyl triplet and methylene quartet for 2 . In addition, the number of observed peak sets for methylene protons was only half the number of existing methylene groups for the oligomers of $n=3,5$ and 7 or ((number of existing methylenes)-1)/ $2+1$ for the oligomers of $n=2,4,6$ and 8 . This profile may be explained in terms of a conformation that is symmetrical with respect to the central methylene (oligomers of $n=2,4,6$ and 8 ) or the central fluorene group (oligomers of $n=3,5$ and 7), such as the crystal structures of 2 of $n=6$ and 5 of $n=5$ shown in Figure 7, if the conformation is stable in solution. A fast exchange between different conformations may also lead to a simple NMR profile. However, fast conformational dynamics in solution seem unreasonable because clear NOE correlations were observed that support a stable all-trans conformation as follows:

In the NOESY spectra of all oligomers analyzed here, all in-chain methylene protons indicated correlation peaks with one or two different methylene groups in addition to aromatic protons. This finding is best interpreted assuming an all-trans conformation as illustrated in Figure 10; only the neighboring groups in such a conformation will show correlation peaks in the NOESY spectra. Hence, methylene protons were assigned as summarized in Tables 3 and 4, assuming an all-trans conformation, which is consistent with the regular numerical relations between the number of observed methylene signals and the existing methylene groups noted above.

Aromatic signals were also assigned using the 2D NMR information. The observed NOE signals were interpreted to correlate the protons at the 1- and 8-positions of the fluorene ring, denoted by $\mathrm{H}_{\mathrm{A} \sim \mathrm{D} 1}$ in Figure 10, and the methylene groups in the vicinity. The position of each fluorene ring was assigned in this way. The peak assignments of the remaining aromatic protons were completed using the COSY information. NOE correlations between protons of neighboring fluorene units in stacked conformation were also observed, although they are not shown in Figure 10 for clarity.

It is noteworthy that aromatic proton signals of all samples of $\mathbf{2}$ were within the range of 5.6-7.1 p.p.m. This is in stark contrast to the fact that poly(9,9-dimethyl-2-vinylfluorene $)^{53}$ and poly(2-vinylfluorene) (Nakano T., unpublished results), which most probably have a flexible conformation in solution, showed their aromatic proton 
a

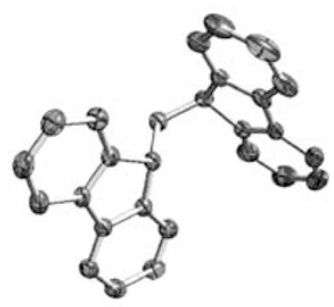

c

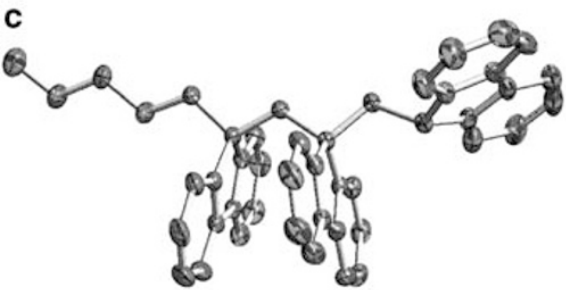

e

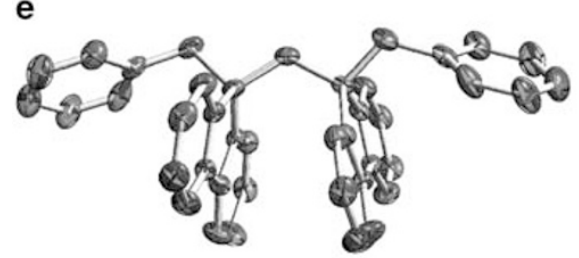

g b

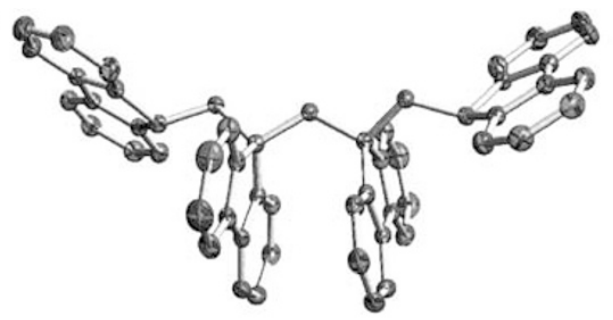

f

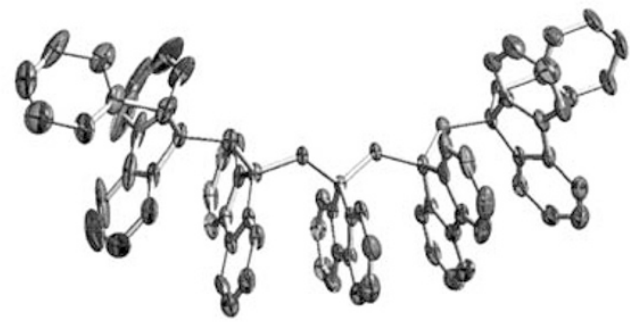

h

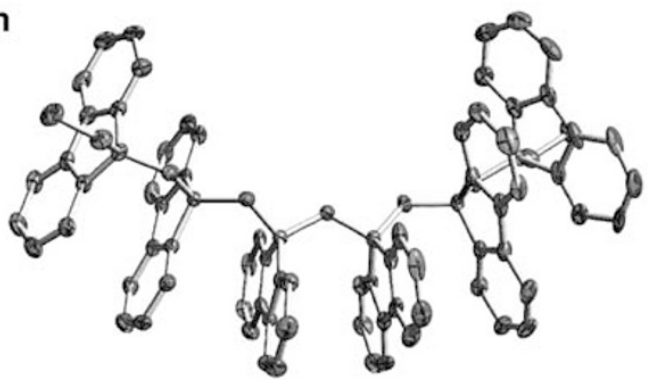

Figure 7 Crystal structures of oligo(DBF)s 1 ( $n=2$ (a) and $n=4$ (b)), $\mathbf{3}(n=3)$ (c), 4 ( $n=4)$ (d), 5 ( $n=2$ (e) and $n=5$ (f)), and 2 ( $n=2$ (g) and $n=6$ (h)). Hydrogen atoms are omitted for clarity. Reproduced with permission from Nakano et al. ${ }^{15}$ Copyright (2003) American Chemical Society.

signals in a much lower magnetic-field range (6-8 p.p.m.). This supports the stable $\pi$-stacked conformation of 2 throughout the chain in solution.

The aromatic proton signals of $\mathbf{1}$ appeared in a wider chemical shift range compared with those of 2 , suggesting that 1 may have a less regular $\pi$-stacked conformation. However, the samples of 1 of $n=4$ and larger showed all aromatic signals, except for a doublet with a four-proton intensity at ca. 7.5 p.p.m., in the range of 5.6-7.2 p.p.m., similar to all samples of 2 , indicating that the most part of 1 of $n=4$ or larger has a regular $\pi$-stacked conformation similar to that of 2 . Exceptional four-proton intensity signals are due to the 4- and 5positions of the terminal fluorene rings according to the peak assignments described above. This may indicate that the terminal fluorene rings of $\mathbf{1}$ are flipped, as observed in the crystal structures of $\mathbf{1}$.

The signals of 1 of $n=2$ were similar to those of fluorene in the chemical shift range, implying that this oligomer does not have a $\pi$-stacked conformation. In the sample of 1 of $n=3$, both flipped and stacked conformation may exist because the spectral profile in the aromatic region is just between that of the longer oligomer and the shorter one.

\section{SOLUTION STRUCTURE OF $\pi$-STACKED POLY(DBF): THEORETICAL ${ }^{1} \mathrm{H}$ NMR ANALYSES}

To rationally connect the NMR spectral information to the solution conformation of oligomers, the chemical shifts of the main-chain methylene and terminal methine or ethyl protons were computationally estimated by density functional theory ${ }^{54}$ calculation for some optimized conformers of 1 of $n=2$ and 2 of $n=2$ and 4 . The conformer structures optimized by the semiempirical PM5 method ${ }^{33}$ are shown in Figure 11, with their $\mathrm{H}_{\mathrm{f}}$ (PM5) and theoretical chemical shifts obtained by the LORG method ${ }^{55}$ using $\mathrm{B}^{5} 8^{56}$ exchange and LYP ${ }^{57}$ correlation functionals. The $\mathrm{H}_{\mathrm{f}}$ values of the conformers having identical chemical structures were similar, indicating that all conformers shown in the figures could contribute to the experimental NMR spectra at similar probabilities.

Before application of the density functional theory method to the oligomers, the accuracy of the density functional theory chemical shift calculation was tested using fluorene, 9-methylfluorene, and superphane, which consist of methylene, methine and an aromatic ring and are expected to have little conformational freedom. The experimental $-\mathrm{CH}_{2}$ shift for fluorene was 3.95 p.p.m. $\left(\mathrm{CDCl}_{3}, 500 \mathrm{MHz}, \mathrm{Me}_{4} \mathrm{Si}\right)$ and 


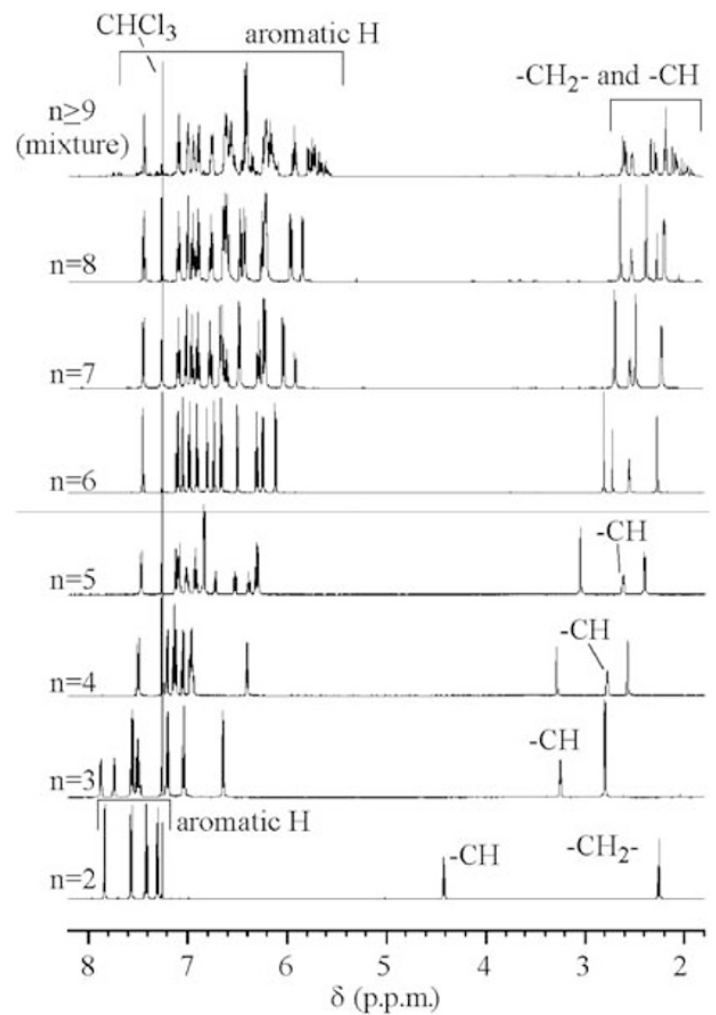

Figure $8{ }^{1} \mathrm{H}$ NMR spectra of oligo(DBF)s (1) $\left(600 \mathrm{MHz}, \mathrm{CDCl}_{3}\right.$, r.t.). Reproduced with permission from Nakano et al. ${ }^{15}$ Copyright (2003) American Chemical Society.

that for superphane was 2.98 p.p.m., ${ }^{58}$ whereas the calculated shifts were 3.87 and 3.29 p.p.m. for fluorene and superphane, respectively. The experimental $-\mathrm{CH}_{3}$ and methine shifts for 9-methylfluorene were 1.53 and 3.95 p.p.m., respectively $\left(\mathrm{CDCl}_{3}, 500 \mathrm{MHz}, \mathrm{Me}_{4} \mathrm{Si}\right)$, and the corresponding calculated values were 1.43 and 4.03 p.p.m. These results indicate that the theoretical calculation in this study may contain an error of $0.1-0.3$ p.p.m.

Conformers $\mathbf{1 A}_{\mathbf{2}}-\mathbf{1} \mathbf{C}_{2}$ were evaluated for $\mathbf{1}$ of $n=2$. The calculated methylene shift of $\mathbf{1 A}_{\mathbf{2}}$ deviated from the experimental value by 1.6 p.p.m., and one of the calculated methine shifts of $\mathbf{1 B}_{2}$ deviated from the experimental value by 2.0 p.p.m., suggesting that these are not the most plausible conformers. In contrast, the deviations of the calculated methylene and methine shifts of $\mathbf{1} \mathbf{C}_{2}$ from the experimental values were only 0.4 and 0.1 p.p.m., respectively. These results suggest that $\mathbf{1 C}_{2}$, in which the two fluorenyl groups are flipped, is the most probable conformer, although other conformers could also exist in conformational dynamics.

Conformers $\mathbf{2} \mathrm{A}_{2}-\mathbf{2} \mathrm{C}_{2}$ for $\mathbf{2}$ of $n=2$ were generated and subjected to shift calculations. The theoretical shifts of the central methylene protons of conformers $\mathbf{2} \mathbf{A}_{2}$ and $\mathbf{2} \mathbf{B}_{2}$ were rather close to the experimental shifts, whereas that of $2 \mathrm{C}_{2}$ deviated from the observed value by 1.3 p.p.m. Therefore, $2 \mathrm{C}_{2}$ may not be reasonable. The predicted chemical shift for one of the terminal methylene groups of $\mathbf{2 B}_{2}$ largely deviated from the experimental value, suggesting that $2 \mathrm{~A}_{2}$ having a $\pi$ stacked conformation is the most plausible. Although it is noticeable that the experimental terminal methyl shift of $2 \mathbf{A}_{2}$ deviated from the predicted value by $\sim 0.8$ p.p.m., this may indicate that the terminal ethyl groups rotate relatively fast and do not result in an accurate shift in the calculation of a single conformer. Hence, flipped and stacked conformations were suggested by the NMR shift calculation for 1 of

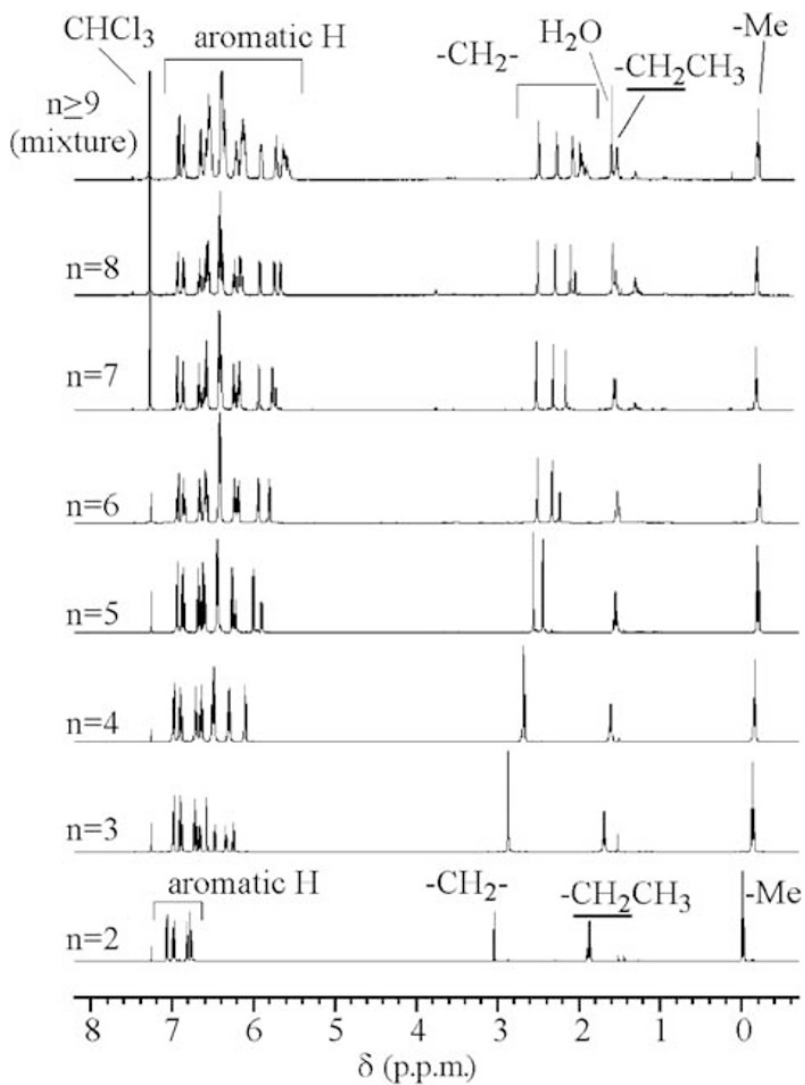

Figure $9{ }^{1} \mathrm{H}$ NMR spectra of oligo(DBF)s (2) $\left(500 \mathrm{MHz}, \mathrm{CDCl}_{3}\right.$, r.t.). Reproduced with permission from Nakano et al. ${ }^{15}$ Copyright (2003) American Chemical Society.

$n=2$ and 2 of $n=2$, respectively. As in crystal, an ethyl or a larger group may prevent the rotation of terminal fluorene units and force it into a stacked form.

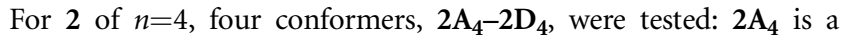
model of a flawlessly stacked conformation, and $\mathbf{2} \mathbf{B}_{4}$ and $\mathbf{2} \mathbf{C}_{4}$ are models of stacked conformations with a 'kink.' Although the models with a kink were predicted to show a remarkable upfield shift in mainchain methylene signals ( $\delta 1-0.7$ p.p.m.) in the vicinity of the kink, no peak was observed in such a high-magnetic-field range in the experimental spectra. In addition, the calculated methylene shifts of $\mathbf{2 A}_{4}$ were rather close to the experimental data. Therefore, $\mathbf{2} \mathbf{A}_{\mathbf{4}}$ is considered to be the most plausible conformation. In this case also, calculated shifts of the terminal methyl protons significantly deviated from the observed values, probably because of the relatively fast motion of the terminal ethyl group as noted above.

As described here, the chemical shift calculation seems to be an effective method of obtaining information on the oligomer conformation. Although longer oligomers and polymers were not subjected to chemical shift calculation, their experimental methylene shifts seem to converge into a value around 2 p.p.m., and no peaks of the methylene group were observed in a range higher than 1 p.p.m. in the spectra. This suggests that the longer oligomers and polymers have a stable $\pi$-stacked conformation without a kink in the chain.

\section{CONFORMATIONAL SIMULATION ON THE $\pi$-STACKED POLY(DBF) STRUCTURE}

Oligomer conformation was evaluated by force field and semiempirical molecular orbital calculations using MM3 ${ }^{*},{ }^{59}$ MMFF $94 s,{ }^{60}$ and COMPASS $^{61}$ force fields and by the semiempirical PM5 $5^{33}$ method. 
Table $3{ }^{1}$ H NMR Chemical shifts ( $\delta$, p.p.m.) of Oligo(dibenzofulvene (DBF))s (1)

\begin{tabular}{|c|c|c|c|c|c|c|c|c|}
\hline$n$ & 2 & 3 & 4 & 5 & 6 & 7 & 8 & $\geqslant 9^{b}$ \\
\hline $\mathrm{H}_{\mathrm{A}}$ & $4.42(t)$ & $3.25(t)$ & $2.78(\mathrm{t})$ & $2.64(t)$ & $2.56(t)$ & $2.55(t)$ & $2.53(\mathrm{t})$ & 2.62-1.88 (methylene protons) \\
\hline $\mathrm{H}_{\mathrm{B}}$ & $2.26(d)$ & $2.80(d)$ & $2.57(d)$ & $2.42(d)$ & $2.28(d)$ & $2.23(d)$ & $2.20(d)$ & \\
\hline $\mathrm{H}_{\mathrm{C}}$ & & & $3.28(\mathrm{~s})$ & $3.06(\mathrm{~s})$ & $2.82(\mathrm{~s})$ & $2.70(\mathrm{~s})$ & $2.64(\mathrm{~s})$ & \\
\hline $\mathrm{H}_{\mathrm{D}}$ & & & & & $2.73(\mathrm{~s})$ & 2.49 (s) & 2.38 (s) & \\
\hline $\mathrm{H}_{\mathrm{E}}$ & & & & & & & $2.27(\mathrm{~s})$ & \\
\hline $\mathrm{H}_{\mathrm{A} 1}$ & $7.57(d)$ & $6.64(d)$ & $6.41(d)$ & $6.31(\mathrm{~d})^{\dagger}$ & $6.25(d)$ & $6.23(d)$ & $6.22(d)^{\dagger}$ & 5.55-7.44 (aromatic protons) \\
\hline $\mathrm{H}_{\mathrm{A} 2}$ & $7.30(\mathrm{dd})$ & $7.04(\mathrm{dd})$ & $6.96(\mathrm{dd})^{\dagger}$ & $6.93(\mathrm{dd})$ & $6.91(\mathrm{dd})$ & $6.91(\mathrm{dd})$ & $6.90(\mathrm{dd})$ & \\
\hline $\mathrm{H}_{\mathrm{A} 3}$ & $7.42(\mathrm{dd})$ & $7.20(\mathrm{dd})$ & $7.14(d d)^{*}$ & $7.13(\mathrm{dd})$ & $7.10(\mathrm{dd})$ & $7.10(\mathrm{dd})$ & $7.10(\mathrm{dd})$ & \\
\hline $\mathrm{H}_{\mathrm{A} 4}$ & $7.84(d)$ & $7.56(d)$ & 7.50 (d) & $7.48(d)$ & 7.46 (d) & $7.45(d)$ & 7.44 (d) & \\
\hline $\mathrm{H}_{\mathrm{B} 1}$ & & $7.74(d)$ & 7.05 (d) & $6.85(d)^{*}$ & $6.74(d)$ & $6.68(d)$ & $6.64(d)$ & \\
\hline $\mathrm{H}_{\mathrm{B} 2}$ & & $7.49(\mathrm{dd})^{*}$ & $6.97(\mathrm{dd})^{\dagger}$ & $6.85(\mathrm{~m})^{*}$ & $6.81(\mathrm{dd})$ & $6.79(\mathrm{dd})$ & $6.77(\mathrm{dd})$ & \\
\hline $\mathrm{H}_{\mathrm{B} 3}$ & & $7.51(\mathrm{dd})^{*}$ & $7.13(\mathrm{dd})^{*}$ & $7.02(\mathrm{~m})$ & $6.98(\mathrm{dd})$ & $6.97(\mathrm{dd})$ & $6.95(\mathrm{dd})$ & \\
\hline $\mathrm{H}_{\mathrm{B} 4}$ & & $7.88(d)$ & 7.22 (d) & 7.10 (d) & 7.06 (d) & 7.03 (d) & 7.01 (d) & \\
\hline $\mathrm{H}_{\mathrm{C} 1}$ & & & & $6.33(\mathrm{~d})^{\dagger}$ & $6.12(d)$ & $6.04(d)$ & $5.96(d)$ & \\
\hline $\mathrm{H}_{\mathrm{C} 2}$ & & & & $6.40(\mathrm{dd})$ & $6.31(\mathrm{dd})$ & $6.29(\mathrm{dd})$ & $6.25(\mathrm{dd})^{\dagger}$ & \\
\hline $\mathrm{H}_{\mathrm{C} 3}$ & & & & $6.74(\mathrm{dd})$ & $6.67(\mathrm{dd})$ & $6.66(d d)$ & $6.61(\mathrm{dd})^{*}$ & \\
\hline $\mathrm{H}_{\mathrm{C} 4}$ & & & & $6.54(d)$ & $6.50(d)$ & $6.49(d)^{*}$ & $6.43(d)$ & \\
\hline $\mathrm{H}_{\mathrm{D} 1}$ & & & & & & 5.93 (d) & $5.85(d)$ & \\
\hline $\mathrm{H}_{\mathrm{D} 2}$ & & & & & & $6.24(d d)$ & $6.22(\mathrm{dd})^{\dagger}$ & \\
\hline $\mathrm{H}_{\mathrm{D} 3}$ & & & & & & $6.62(\mathrm{dd})$ & $6.61(\mathrm{dd})^{*}$ & \\
\hline $\mathrm{H}_{\mathrm{D} 4}$ & & & & & & $6.50(d)^{*}$ & $6.47(d)$ & \\
\hline
\end{tabular}

aSee Figure 10 for proton numbering. Spectra were recorded in $\mathrm{CDCl}_{3}$ at room temperature $(600 \mathrm{MHz})$. Residual $\mathrm{CHCl}_{3}$ signal $\left(7.26 \mathrm{p} . \mathrm{p} . \mathrm{m}\right.$.) was used as an internal reference. ${ }^{*}$ and ${ }^{\dagger}$ indicate interchangeable assignments.

${ }^{\mathrm{b}} \mathrm{A}$ polymer ( $M n=1700$ (vs oligo(DBF), $n=9.6, n>9$ mixture). Reproduced with permission from Nakano et al. ${ }^{15}$ Copyright (2003) American Chemical Society.

Table $4{ }^{1} \mathrm{H}$ NMR Chemical shifts ( $\delta$, p.p.m.) of Oligo(dibenzofulvene (DBF))s (2)a

\begin{tabular}{|c|c|c|c|c|c|c|c|c|}
\hline$n$ & 2 & 3 & 4 & 5 & 6 & 7 & 8 & $\geqslant 9^{b}$ \\
\hline $\mathrm{Me}-$ & $-0.01(\mathrm{t})$ & $-0.14(t)$ & $-0.16(t)$ & $-0.20(\mathrm{t})$ & $-0.22(t)$ & $-0.23(t)$ & $-0.24(\mathrm{t})$ & $-0.25(t)$ \\
\hline $\mathrm{H}_{\mathrm{A}}$ & $1.88(q)$ & $1.69(q)$ & $1.61(q)$ & $1.55(\mathrm{q})$ & $1.53(q)$ & $1.51(q)$ & $1.50(q)$ & $1.49(q)$ \\
\hline $\mathrm{H}_{\mathrm{B}}$ & 3.05 (s) & $2.87(\mathrm{~s})$ & $2.68(\mathrm{~s})$ & $2.56(\mathrm{~s})$ & $2.51(\mathrm{~s})$ & $2.48(s)$ & $2.47(\mathrm{~s})$ & $2.46-1.86$ (methylene protons) \\
\hline $\mathrm{H}_{\mathrm{C}}$ & & & $2.67(\mathrm{~s})$ & $2.45(\mathrm{~s})$ & $2.34(\mathrm{~s})$ & $2.28(\mathrm{~s})$ & $2.25(\mathrm{~s})$ & \\
\hline$H_{D}$ & & & & & $2.24(\mathrm{~s})$ & $2.12(\mathrm{~s})$ & $2.07(\mathrm{~s})$ & \\
\hline $\mathrm{H}_{\mathrm{E}}$ & & & & & & & $2.00(\mathrm{~s})$ & \\
\hline $\mathrm{H}_{\mathrm{A} 1}$ & $6.77(d)$ & $6.58(d)$ & $6.50(d)^{*}$ & $6.45(d)^{*}$ & $6.42(d)^{\dagger}$ & $6.40(d)^{\dagger}$ & $6.39(\mathrm{~d})^{\dagger}$ & 5.52-6.91 (aromatic protons) \\
\hline $\mathrm{H}_{\mathrm{A} 2}$ & $6.83(d d)$ & $6.72(d d)$ & $6.71(\mathrm{dd})$ & $6.68(d d)$ & $6.66(\mathrm{dd})$ & $6.65(d)$ & $6.64(\mathrm{dd})$ & \\
\hline $\mathrm{H}_{\mathrm{A} 3}$ & $6.98(d d)$ & $6.90(\mathrm{dd})$ & $6.90(\mathrm{dd})$ & $6.87(\mathrm{dd})$ & $6.86(\mathrm{dd})$ & $6.85(d)$ & $6.85(\mathrm{dd})$ & \\
\hline $\mathrm{H}_{\mathrm{A} 4}$ & $7.07(\mathrm{~d})$ & $6.98(d)$ & $6.98(d)$ & $6.94(d)$ & $6.93(d)$ & $6.92(d)$ & $6.92(d)$ & \\
\hline $\mathrm{H}_{\mathrm{B} 1}$ & & $6.25(d)$ & $6.10(d)$ & $6.00(d)$ & $5.94(d)$ & $5.91(d)$ & $5.90(d)$ & \\
\hline $\mathrm{H}_{\mathrm{B} 2}$ & & $6.34(\mathrm{dd})$ & $6.30(\mathrm{dd})$ & $6.26(\mathrm{dd})$ & $6.24(\mathrm{dd})$ & $6.22(\mathrm{dd})$ & $6.21(\mathrm{dd})$ & \\
\hline $\mathrm{H}_{\mathrm{B} 3}$ & & $6.66(\mathrm{dd})$ & $6.65(\mathrm{dd})$ & $6.62(\mathrm{dd})^{\dagger}$ & $6.60(\mathrm{dd})^{*}$ & $6.59(\mathrm{dd})$ & $6.58(\mathrm{dd})$ & \\
\hline $\mathrm{H}_{\mathrm{B} 4}$ & & $6.48(d)$ & $6.48(d)^{*}$ & $6.45(d)^{*}$ & $6.42(d)^{\dagger}$ & $6.41(\mathrm{~d})^{\dagger}$ & $6.40(\mathrm{~d})^{\dagger}$ & \\
\hline $\mathrm{H}_{\mathrm{C} 1}$ & & & & $5.90(d)$ & $5.81(d)$ & $5.75(d)$ & $5.72(d)$ & \\
\hline $\mathrm{H}_{\mathrm{C} 2}$ & & & & $6.22(\mathrm{dd})$ & $6.19(\mathrm{dd})$ & $6.16(\mathrm{dd})^{\ddagger}$ & $6.15(\mathrm{dd})^{\ddagger}$ & \\
\hline $\mathrm{H}_{\mathrm{C} 3}$ & & & & $6.60(\mathrm{dd})^{\dagger}$ & $6.58(\mathrm{dd})^{*}$ & $6.56(d d)^{*}$ & $6.55(\mathrm{dd})^{*}$ & \\
\hline $\mathrm{H}_{\mathrm{C} 4}$ & & & & $6.45(d)^{*}$ & $6.42(d)^{\dagger}$ & $6.40(d)^{\dagger}$ & $6.39(d)^{\dagger}$ & \\
\hline $\mathrm{H}_{\mathrm{D} 1}$ & & & & & & $5.70(d)$ & $5.65(d)$ & \\
\hline $\mathrm{H}_{\mathrm{D} 2}$ & & & & & & $6.15(\mathrm{dd})^{\ddagger}$ & $6.13(\mathrm{dd})^{\ddagger}$ & \\
\hline $\mathrm{H}_{\mathrm{D} 3}$ & & & & & & $6.56(d d)^{*}$ & $6.54(d d)^{*}$ & \\
\hline $\mathrm{H}_{\mathrm{D} 4}$ & & & & & & $6.38(d)^{\dagger}$ & $6.36(d)$ & \\
\hline
\end{tabular}

aSee Figure 10 for proton numbering. Spectra were recorded in $\mathrm{CDCl}_{3}$ at room temperature $(500 \mathrm{MHz})$. Residual $\mathrm{CHCl}_{3}$ signal $\left(7.26\right.$ p.p.m.) was used as an internal reference. ${ }^{*},{ }^{\dagger}$ and ${ }^{\ddagger}$ indicate interchangeable assignments.

${ }^{b}$ A polymer ( $M_{n}=1890$ (vs oligo(DBF), $n=10.4, n>9$ mixture). Reproduced with permission from Nakano et al. ${ }^{15}$ Copyright (2003) American Chemical Society.

First, Monte Carlo conformational searches with $\mathrm{MM}^{*}$ and MMFF94s force fields were conducted on a DBF hexamer having ethyl groups at the chain terminals $(2, n=6)$ using a MacroModel $6.0^{62}$ software package (Schroedinger, Portland, OR, USA). The relative arrangements of the fluorene moieties were fixed, and the dihedral angles around the 12 main-chain bonds were changed at an interval of $60^{\circ}$ in generating initial geometries (Figure 12). Each conformer generated in the Monte Carlo process was fully minimized using 

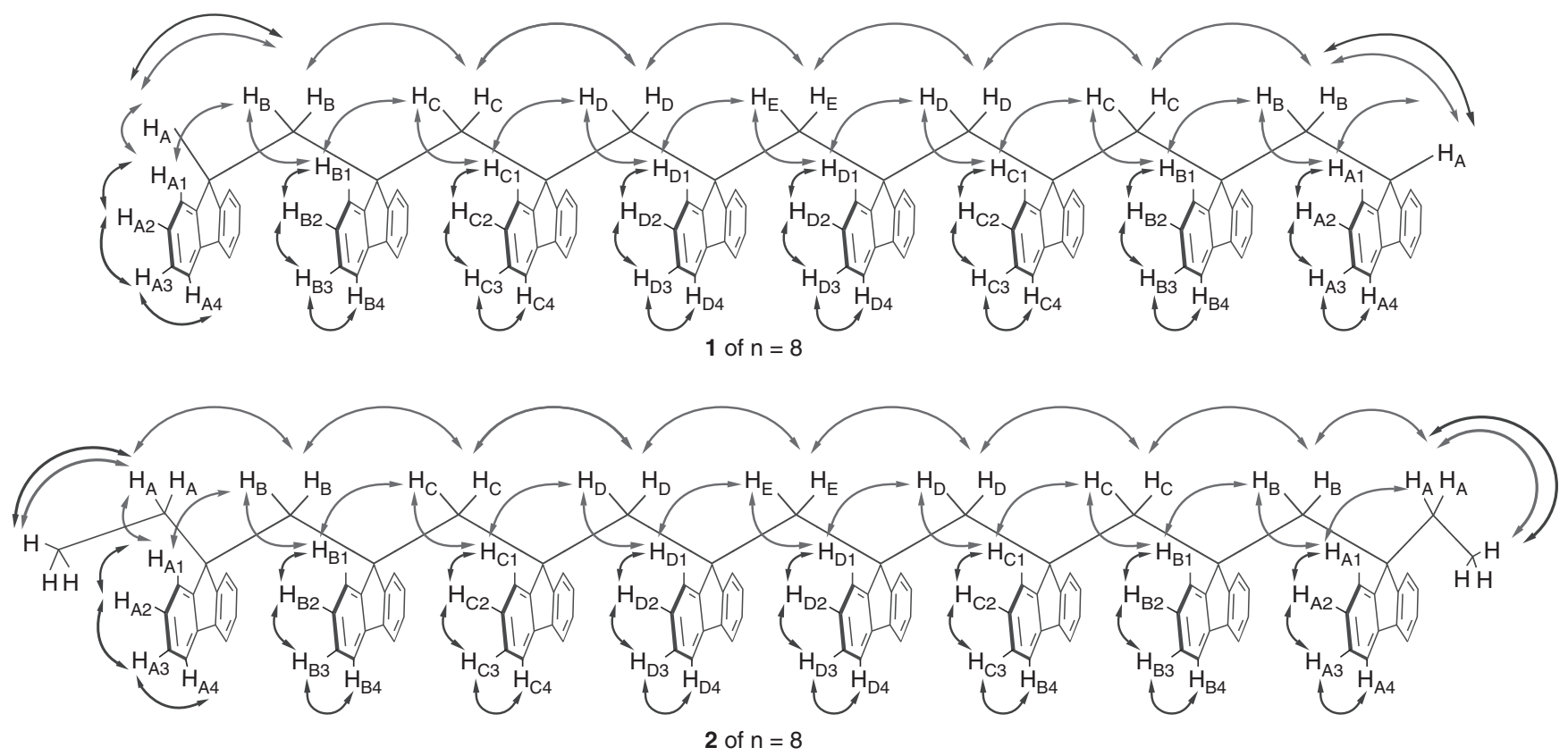

Figure 10 Structures of 1 and 2 of $n=8$ with the proton numbering systems. COSY and NOESY correlations were marked by blue and red arrows, respectively. NOESY correlations between aromatic protons are omitted. Reproduced with permission from Nakano et al. ${ }^{15}$ Copyright (2003) American Chemical Society. A full colour version of this figure is available at the Polymer Journal online.

MM3* or MMFF94s force field until the RMS residue reduced to below $0.05 \mathrm{kcal} \mathrm{mol}^{-1}$ per $\AA$ or 1000 iterations were achieved. Conformers most frequently found within a $15 \mathrm{~kJ} \mathrm{~mol}^{-1}$ energy range from the global minimum were considered to be the most stable ones.

In this simulation, two distinctive structures were found to be the most stable conformations using $\mathrm{MM}^{*}$ and MMFF94s force fields out of $20000\left(\mathrm{MM}^{\star}\right.$ ) and 19550 (MMFF94s) conformers. These two most stable conformers were further minimized by the PM5 method to afford structures $\mathbf{2 A}_{\mathbf{6}}$ and $\mathbf{2} \mathbf{B}_{\mathbf{6}}$, as shown in Figure 13 . Structure $\mathbf{2 A}_{\mathbf{6}}$ was similar to the crystal structure (Figure 7 ), whereas structure $\mathbf{2 B}_{\mathbf{6}}$ had a partially trans-gauche-like structure. The two conformers indicated similar values of $\mathrm{H}_{\mathrm{f}}$ by the PM5 method.

Next, the stability of conformations $\mathbf{2}_{\mathbf{6}}$ and $\mathbf{2}_{\mathbf{6}}$ was tested by molecular dynamics (MD) simulations using the COMPASS force field under NVT conditions with Berendsen's thermostat ${ }^{63}$ implemented in the Discover module of the Material Studio 2.0 (Accelrys, San Diego, CA, USA) software package. Simulations were performed under a constant NVT condition in which the numbers of atoms, volume and thermodynamic temperature were held constant. The step time was $1 \mathrm{fs}$ and the decay constant was 0.1 ps. Conformations obtained through MD simulation were saved in trajectory files at every 5 or $10 \mathrm{ps}$ and were optimized by MM simulation. The results are shown in Figure 13 (right-hand side). Whereas conformation $\mathbf{2} \mathbf{A}_{\mathbf{6}}$ did not largely change in the $\mathrm{MD}$ simulation at $300 \mathrm{~K}$ for $10 \mathrm{~ns}$ to yield structure $2 \mathbf{A}_{\mathbf{6}^{\prime}}$, conformation $\mathbf{2 B}_{\mathbf{6}}$ quickly changed into a mostly all-trans, $\pi$-stacked conformation with a kink (gauche-gauche main-chain conformation) $\left(\mathbf{2 B}_{\mathbf{6}^{\prime}}\right)$ in the middle of the chain at $300 \mathrm{~K}$ within $0.1 \mathrm{~ns}$, and structure $\mathbf{2 B}_{\mathbf{6}^{\prime}}$ did not significantly change within $8 \mathrm{~ns}$. These results suggest that a $\pi$-stacked conformation is preferred under dynamic conditions, whereas several different conformers, including the $\pi$-stacked structure, may have similar steric energies under static conditions.

The conformational stability test was extended to a model of the polymer $(2, n=15)$. In this case, an all-trans 15 -mer and an alternating trans-gauche 15-mer were generated as initial conformations and optimized using the COMPASS force field with the Fletcher-Reeves ${ }^{64}$ conjugate gradient algorithm until the RMS residue reduced to below $0.01 \mathrm{kcal} \mathrm{mol}^{-1}$ per $\AA\left(2 \mathrm{~A}_{15}\right.$ and $\mathbf{2} \mathbf{B}_{15}$ in Figure 14$)$. The molecular mechanically optimized structures were then subjected to MD simulations. The all-trans model, $\mathbf{2} \mathbf{A}_{\mathbf{1 5}}$, remained in the $\pi$-stacked structure throughout the simulation at $300 \mathrm{~K}$ for $15 \mathrm{~ns}$. Even in the simulation at $600 \mathrm{~K}$ for $15 \mathrm{~ns}$, the $\pi$-stacked structure of $\mathbf{2 A _ { 1 5 }}$ was only partially distorted; the $\pi$-stacked sequence remained at a shorter length than the initial structure, and they were connected through gauche-gauche kink structures in the chain. In contrast, structure $2 \mathbf{B}_{15}$ promptly changed into a preferentially all-trans, $\pi$-stacked conformation with a kink at $300 \mathrm{~K}$ within $2 \mathrm{~ns}$ of the simulation time and the structure was found unchanged at $10 \mathrm{~ns}$. These results suggest that the $\pi$-stacked conformation is most preferable for poly(DBF). Although some conformers with a kink in the main chain were observed in the calculations, most of the real molecules are considered to have a $\pi$ stacked structure throughout the chain, based on the discussions regarding NMR spectra in the preceding section.

\section{PHOTOPHYSICAL PROPERTIES OF $\pi$-STACKED POLY(DBF)}

The absorption and emission spectra of the oligomers $(n=2-8)$ and polymers $(n \geqslant 9)$ of 1 and 2 indicated characteristic profiles on the basis of their structures. The absorption spectra are shown in Figure 15. Oligomer 1 of $n=2$ bearing two fluorene groups indicated slight hyperchromicity relative to 9-methylfluorene, the model for the monomeric unit, which is obvious in the $240-280 \mathrm{~nm}$ region, whereas oligomers 1 of $n=3-8$ and the polymer $\left(M_{\mathrm{n}}=1700, n=9.6\right.$, mixture of $n \geqslant 9)$ exhibited significant hypochromicity. In addition, all samples of 1 of $n=3$ and larger showed a red shift in absorption bands. As for oligomers 2 , all samples, including the one of $n=2$, exhibited hypochromicity and a red shift.

Hypochromic effects have been reported for stacked base pairs in a double helical strand in DNAs ( $\sim 40 \%$ decrease in absorption at $260 \mathrm{~nm}$ for Escherichia coli DNA relative to its enzymic digest, a 

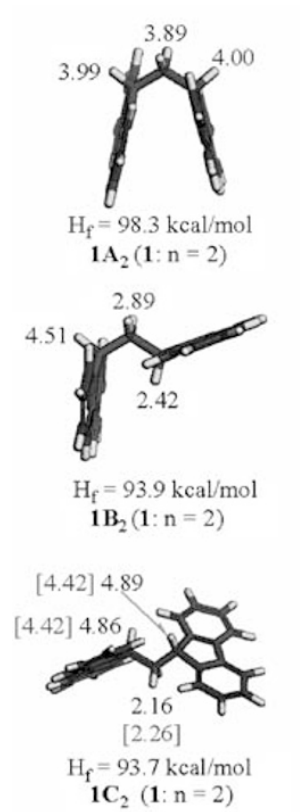
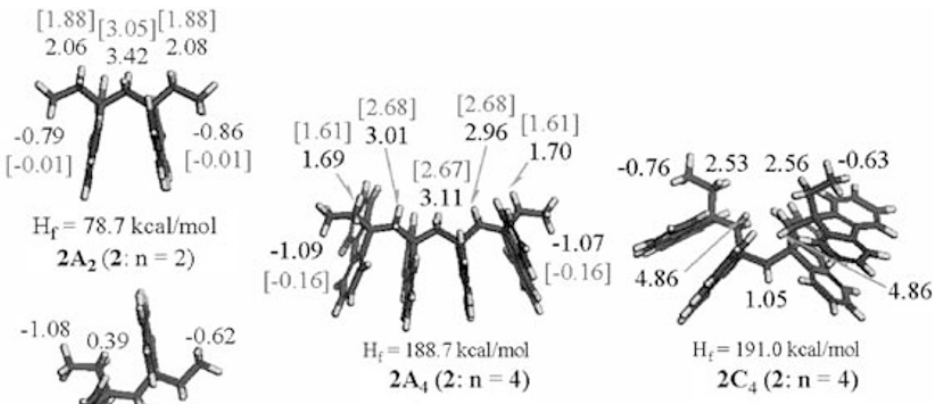

$\mathrm{H}_{\mathrm{f}}=77.8 \mathrm{kcal} / \mathrm{mol}$ $2 \mathrm{~B}_{2}(\mathrm{2}: \mathrm{n}=2)$
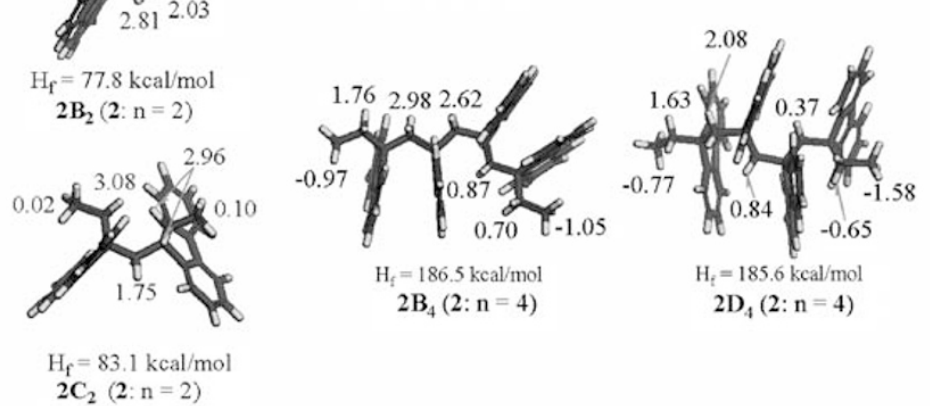

$2 B_{4}(2: n=4)$

$2 \mathrm{D}_{4}(2: \mathrm{n}=4$

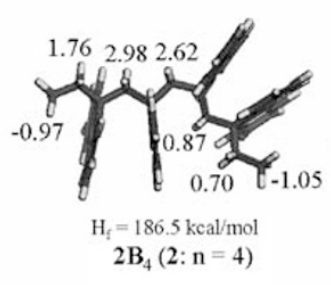

$2 C_{2}(2: n=2)$

Figure 11 Conformers of $1(n=2)$ and $2(n=2$ and $n=4)$ and calculated chemical shifts of methylene protons. The values in square brackets are the experimental chemical shifts. Reproduced with permission from Nakano et al. ${ }^{15}$ Copyright (2003) American Chemical Society.

mixture of monomers). ${ }^{65,66}$ Therefore, the hypochromicity described above is consistent with the above discussion that the oligomers and polymers studied here have a $\pi$-stacked conformation in solution. The degree of hypochromicity found for the polymers (mixture of $n \geqslant 9$ ) in this study is larger than that for DNAs. This may indicate that $\pi$-electron systems are more densely packed in the present systems than in those in DNAs. The fact that $\mathbf{1}$ of $n=2$ was hyperchromic, ${ }^{65}$ whereas 2 of $n=2$ was hypochromic, supports the conclusion from the ${ }^{1} \mathrm{H}$ NMR studies that the former compound does not have a stacked conformation whereas the latter does.

The observed red shift of absorption bands indicates that electronic interaction between neighboring fluorene units in the ground state lowered the excitation energy of the oligomers or polymers. In main-chain-conjugated polymers, a longer chain length results in a significantly reduced band gap. ${ }^{67,68}$ Electronic interaction between closely stacked but not covalently bonded aromatic groups may also make the band gap narrower from the present results, although the effect seems to be smaller compared with that for main-chainconjugated polymers. ${ }^{68}$

To more quantitatively evaluate the red shift and the hypochromicity, the wavelength and molar extinction coefficient $(\varepsilon)$ of the lowestenergy absorption peak were plotted against the chain length $(n)$ of oligomers 2 (Figure 16). The peak-top wavelength increased with the chain length and leveled off around $n=5$ (Figure 16a). In addition, $\varepsilon$ at the peak top decreased with $n$ and also leveled off around $n=5$ (Figure 16b). These results suggest that in the ground state, the electronic interaction between the stacked fluorene groups may extend over as long as $\sim 5$ units. An exciton may be formed over $\sim 5$ successive monomeric units in a chain upon photoexcitation.

This may be interpreted as follows: DBF oligomers and polymers have a $\pi$-stacked structure in solution as we concluded on the basis of NMR data and theoretical simulations. However, $\pi$-stacked molecules should experience a thermal vibration that does not largely distort the conformation; this may lead to heterogeneity of the stacked

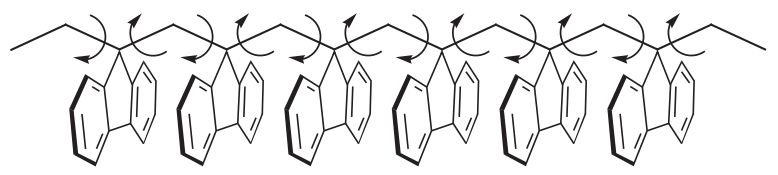

Figure 12 Dihedral angle sets for the Monte Carlo simulation of 2 of $n=6$. Reproduced with permission from Nakano et al. ${ }^{15}$ Copyright (2003) American Chemical Society.

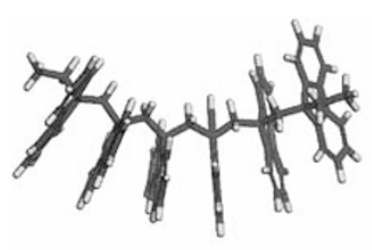

$\mathrm{H}_{\mathrm{f}}=299.05 \mathrm{kcal} / \mathrm{mol}$

$\mathbf{2} \mathrm{A}_{6}$

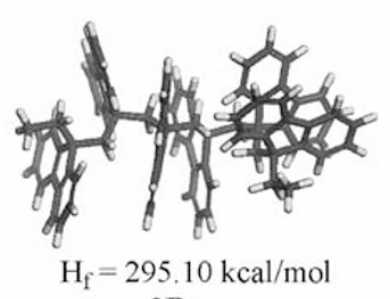

$2 \mathrm{~B}_{6}$

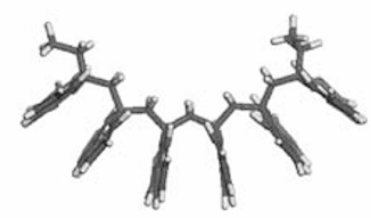

$2 \mathbf{A}_{6}{ }^{\prime}$

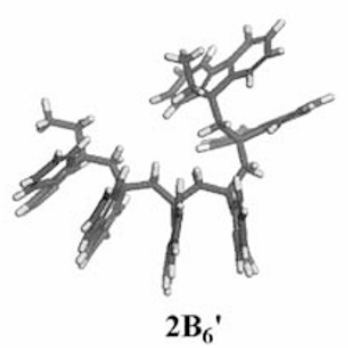

$2 B_{6}{ }^{\prime}$
Figure 13 Conformers of 2 of $n=6$ found most stable in the Monte Carlo simulation and optimized by the PM5 method, $\mathbf{2 \mathbf { A } _ { 6 }}$ (force filed, $M \mathrm{MM}^{*}$ ) and $\mathbf{2 B}_{6}$ (force field, MMFF94s), and those after MD simulation, $\mathbf{2 A}_{\mathbf{6}^{\prime}}$ (300 K, $10 \mathrm{~ns})$ and $\mathbf{2} \mathbf{B}_{\mathbf{6}^{\prime}}(300 \mathrm{~K}, 8.2 \mathrm{~ns})$, starting from $\mathbf{2}_{\mathbf{6}}$ and $\mathbf{2} \mathbf{B}_{\mathbf{6}}$, respectively. Reproduced with permission from Nakano et al. ${ }^{15}$ Copyright (2003) American Chemical Society. 
a starting from all-trans structure, $\mathbf{2} \mathbf{A}_{\mathbf{1 5}}(\mathbf{3 0 0} \mathrm{K})$

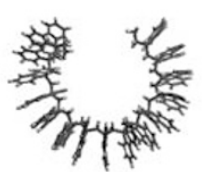

$0 \mathrm{~ns}$

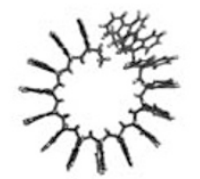

$1 \mathrm{~ns}$

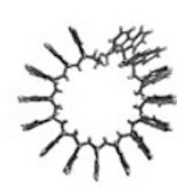

$5 \mathrm{~ns}$

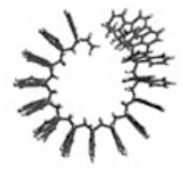

$10 \mathrm{~ns}$

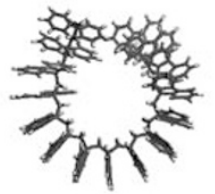

$15 \mathrm{~ns}$

b starting from all-trans structure, $\mathbf{2} \mathbf{A}_{\mathbf{1 5}}(600 \mathrm{~K})$

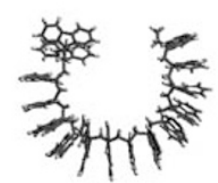

$0 \mathrm{~ns}$

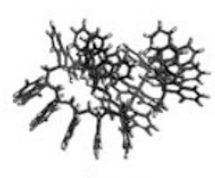

$1 \mathrm{~ns}$

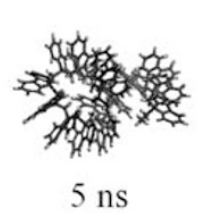

$5 \mathrm{~ns}$

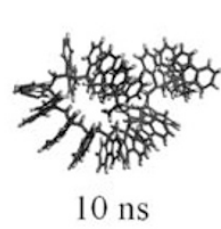

$10 \mathrm{~ns}$

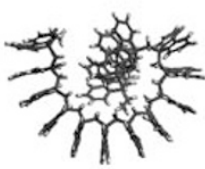

$15 \mathrm{~ns}$

C starting from trans-gauche structure, $\mathbf{2 B}_{\mathbf{1 5}}(300 \mathrm{~K})$

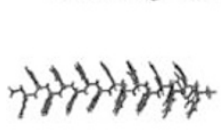

$0 \mathrm{~ns}$

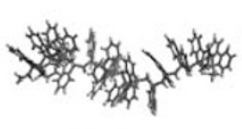

$0.5 \mathrm{~ns}$

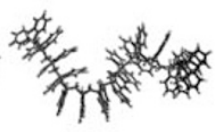

$1 \mathrm{~ns}$

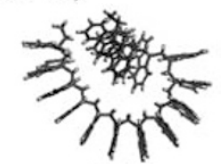

$2 \mathrm{~ns}$

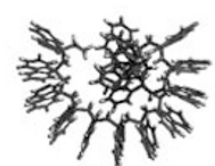

$10 \mathrm{~ns}$

Figure 14 Conformations of 2 of $n=15$ observed during MD simulations: those starting from an all-trans structure at $300 \mathrm{~K}$ (a), those starting from an all-trans structure at $600 \mathrm{~K}(\mathbf{b})$, and those starting from an alternating trans-gauche structure at $300 \mathrm{~K}$ (c). Reproduced with permission from Nakano et al. ${ }^{15}$ Copyright (2003) American Chemical Society.

conformation, that is, the distance between the fluorene groups and main-chain torsion angle can slightly vary part by part in a chain, especially in a relatively short time range within which photoabsorption takes place. The roughly coincidental critical number of fluorene units suggests that $\sim 5$ fluorene units are always in one block of uniformly stacked sequence even at a short time scale. In other words, the dynamic 'persistence length' of a uniformly $\pi$-stacked sequence from the view of photoexcitation covers five monomeric units under the experimental conditions of this study.

An alternative interpretation may be that the electronic interaction of the stacked fluorene groups in the polymer side chain extends inherently up to $\sim 5$ units even for a long, completely uniform 'frozen' $\pi$-stacked polymer. Absorption measurements at an extremely low temperature or in a solid-state matrix that may freeze molecular vibration might provide an answer. Computational studies on the electronic states of poly(DBF) may also be necessary.

Figure 17 shows the emission spectra of $\mathbf{1}$ and $\mathbf{2}$. In the spectra of $\mathbf{1}$ (Figure 17a), those of $n \geqslant 4$ indicated predominant emission bands around $400 \mathrm{~nm}$, whereas that of $n=2$ showed a shorter-wavelength emission band around $310 \mathrm{~nm}$, which was similar in shape and wavelength to that of monomeric fluorene, and that of $n=3$ indicated both bands around 310 and $400 \mathrm{~nm}$. The bands around $400 \mathrm{~nm}$ are considered to arise from an excited dimer or an excimer in which excited energy delocalizes over two neighboring, stacked fluorene units because the band wavelength is rather close to that of the fluorene excimer $^{69}(367 \mathrm{~nm}$, in toluene) and the excited side-chain dimer of poly (2-vinylfluorene $)^{70}(380 \mathrm{~nm}$, in THF). In contrast to 1 , all samples of $\mathbf{2}$ indicated a predominant dimer emission.

As discussed so far, the terminal fluorene moieties are flipped and not stacked in samples of $\mathbf{1}$. The terminal-flipped conformation explains the monomeric fluorene emission from 1 of $n=2$ and 3 . However, the sample of 1 of $n \geqslant 4$ showed only the dimer emission.
This suggests that the energy transfer from the terminal, flipped fluorene moieties to dimer forming, in-chain stacked fluorene moieties quenches monomeric fluorene in the longer oligomers of 1. The predominant dimer emission from all 2 samples is consistent with the fact that all oligomers of 2 have a $\pi$-stacked structure throughout the chain.

The emission wavelength of the dimer emission of $\mathbf{1}$ and $\mathbf{2}$ was slightly red-shifted compared with that of the fluorene excimer ${ }^{69}$ and the excited side-chain dimer in poly(2-vinylfluorene), ${ }^{70}$ which may signify that the arrangement of two fluorene molecules in the excimer is different from that of two fluorene units in oligomers. As can be seen in the crystal structure, side-chain fluorene moieties are so densely packed along the chain that the main-chain bends into a slightly arched shape. Such a close packing of two fluorene units probably enhances the electronic interaction between stacked $\pi$ electrons and, hence, reduces the delocalized excited energy level.

It is noteworthy that the emission profile of oligomer $\mathbf{1}$ of $n=2$ is in sharp contrast to what is expected from 'Hirayama's rule,'71 which predicts that a molecular array with two chromophores connected through three $\mathrm{CH}_{2}$ groups favors excimer formation more than others with more or less $\mathrm{CH}_{2}$ groups between the chromophores. Although in the structure of $\mathbf{1}$ of $n=2$, two fluorenes are connected through three carbons, this oligomer showed only monomer emission. The conformational dynamics of this sample seems to be slower than that of the compounds tested by Hirayama that form a stacked excimer before emission.

\section{ELECTROCHEMICAL PROPERTIES OF $\pi$-STACKED POLY(DBF)}

Stacked $\pi$-electron systems may facilitate charge delocalization. To obtain information on how the stacked fluorene units may affect electronic properties, cyclic voltammetry measurements were performed for oligomers 2 . The experiments were performed in a THF 
solution containing tetrabutylammonium perchlorate as a supporting electrolyte $(0.1 \mathrm{M})$ under $\mathrm{N}_{2}$ flow at room temperature with a conventional three-electrode configuration consisting of a platinum working electrode, an auxiliary platinum electrode and a $\mathrm{Ag} / \mathrm{AgCl}$ reference electrode at a sweep rate of $100 \mathrm{mV} \mathrm{s}^{-1}$. Half-wave potential $\left(\mathrm{E}_{\mathrm{p} / 2}\right)$ values were determined as the potential at the current that was half of the diffusion limiting current.

Samples showed clear oxidation peaks around $1.5-1.7 \mathrm{~V}$, but no clear corresponding reduction peak in the reverse scans from 2 to $0 \mathrm{~V}$ (Figure 18). In addition, the intensity of the oxidation peak gradually decreased in repeated runs, although the peak position was unchanged. These results suggest that the oxidized species may undergo some irreversible reaction on the electrode surface.

Figure 19 shows the dependence of oxidation potential (half-wave potential, $\mathrm{E}_{\mathrm{p} / 2}$ ) on the chain length. The oxidation potential decreased with chain length and seemed to approach a constant value when DP
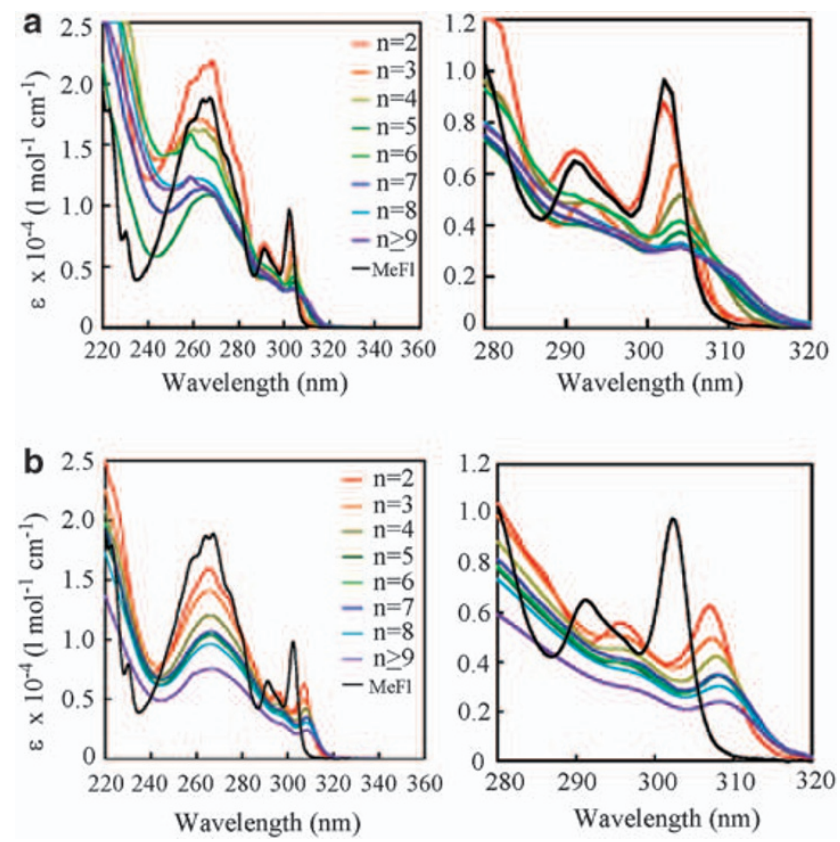

Figure 15 Absorption spectra of oligo(DBF)s 1 (a), 2 (b) and 9methylfluorene (MeFI) as model monomeric units in THF at room temperature. Reproduced with permission from Nakano et al. ${ }^{15}$ Copyright (2003) American Chemical Society. exceeds $\sim 5$. This may mean that a hole is stabilized by delocalization over as many as $\sim 5$ stacked fluorene units. This critical number of fluorene units coincides with those for the changes in the absorption intensity and edge wavelength depending on the chain length. As discussed in the preceding section, this may be ascribed to the proposed dynamic 'persistence length' of a uniformly $\pi$-stacked sequence consisting of five fluorene units or to the nature of charge delocalization through the $\pi$-stacked structure of poly(DBF), which may inherently be limited to five fluorene units even if the chain has a longer, uniform 'frozen' $\pi$-stacked structure. A low-temperature or solid-state study minimizing thermal vibration might provide an answer.

Plots of $\mathrm{E}_{\mathrm{p} / 2}$ against $1 / n$ led to a potential of $1.44 \mathrm{~V}$ (vs $\mathrm{Ag} / \mathrm{AgCl}$ ) at an infinite $n$ by extrapolation (Figure 20). This value may correspond to the oxidation potential (half-wave potential) of a very long chain of poly(DBF).
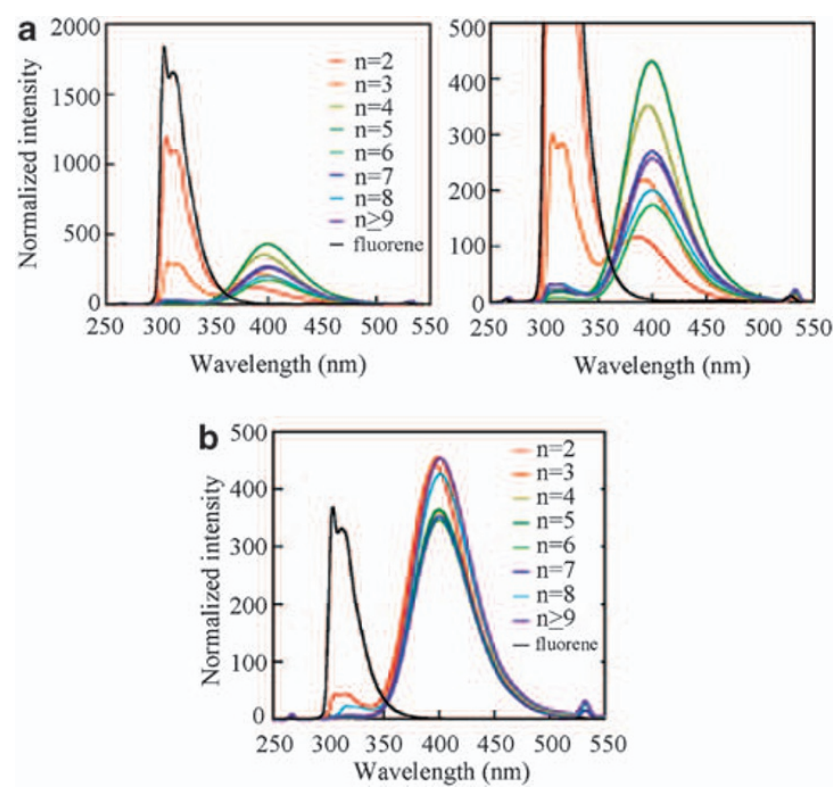

Figure 17 Emission spectra of oligo(DBF)s 1 (a), 2 (b) and fluorene in THF at room temperature $\left(\lambda_{\mathrm{ex}}=267 \mathrm{~nm}\right)$. Intensity was normalized to a constant absorbance at $267 \mathrm{~nm}$. Reproduced with permission from Nakano et al. ${ }^{15}$ Copyright (2003) American Chemical Society.
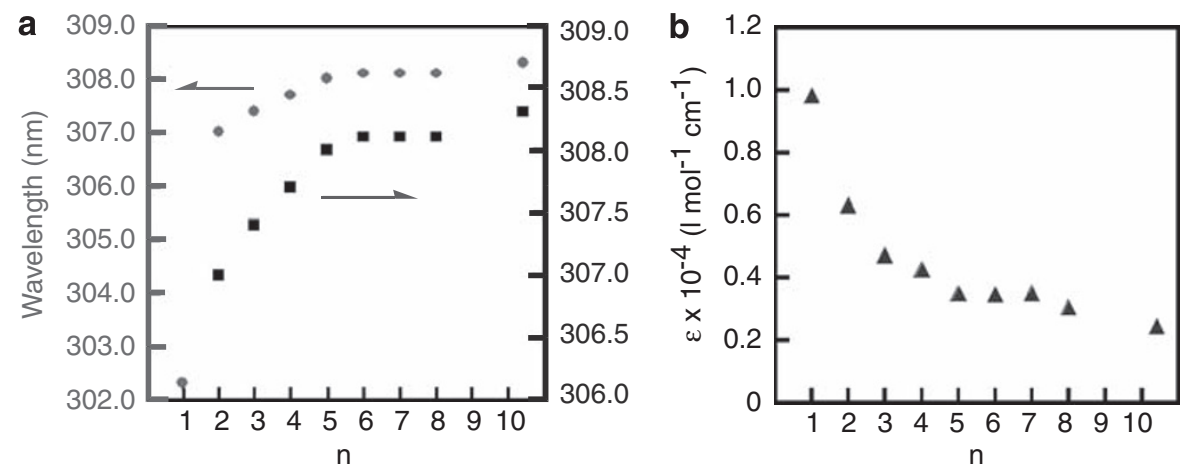

Figure 16 Wavelength-vs- $n$ (a) and molar extinction coefficient $(\varepsilon)$-vs- $n$ (b) plots for the longest wavelength absorption maxima of oligo(DBF)s 2. Data at $n=1$ are for 9 -methylfluorene, and those at $n=10.4$ are for a polymer $\left(M_{\mathrm{n}}=1890\right.$ (vs oligo(DBF)), $\left.\bar{n}=10.4\right)$. Reproduced with permission from Nakano et al. ${ }^{15}$ Copyright (2003) American Chemical Society. 


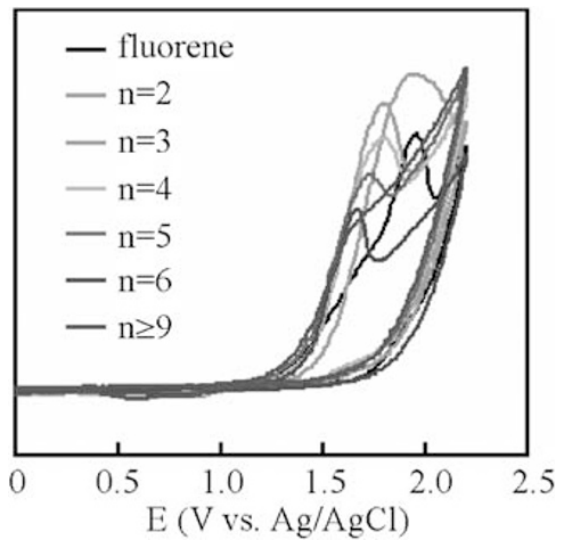

Figure 18 Cyclic voltammograms of oligo(DBF)s (2) and fluorene. Reproduced with permission from Nakano et al. ${ }^{15}$ Copyright (2003) American Chemical Society.

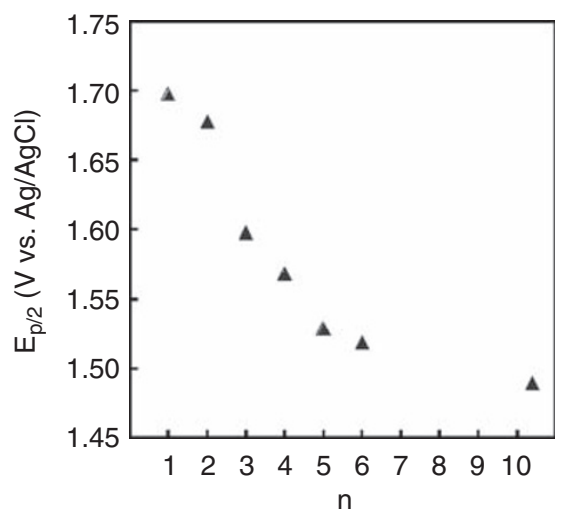

Figure 19 Half-wave potential-vs- $n$ plot for 2. Data at $n=1$ are for fluorene, and those at $n=10.4$ are for a polymer $\left(M_{\mathrm{n}}=1890\right.$ (vs oligo(DBF)), $\left.\bar{n}=10.4\right)$. Reproduced with permission from Nakano et al. ${ }^{15}$ Copyright (2003) American Chemical Society.

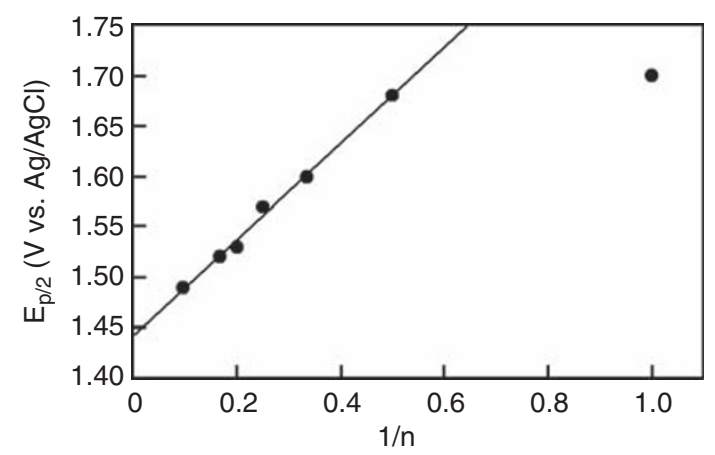

Figure 20 Half-wave potential-vs- $1 / n$ plots for the longest wavelength absorption maxima of oligo(DBF)s 2. Extrapolation of the plot to $1 / n=0$ yielded $1.44 \mathrm{~V}$ vs $\mathrm{Ag} / \mathrm{AgCl}$ ( $1.40 \mathrm{~V}$ vs $\mathrm{SCE}$ ) for a polymer with an infinite number of fluorene moiety. Data at $1 / n=1$ are for fluorene, and those at $1 / n=0.0962$ are for a polymer $\left(M_{\mathrm{n}}=1890\right.$ (vs oligo(DBF)), $\bar{n}=10.4$ ). Reproduced with permission from Nakano et al. ${ }^{15}$ Copyright (2003) American Chemical Society.

\section{CHARGE TRANSPORT AND CHARGE DELOCALIZATION PROPERTIES OF $\pi$-STACKED POLY(DBF)}

Conducting polymers are an important class of material required for organic electronics and optoelectronics. ${ }^{72}$ Although most conducting

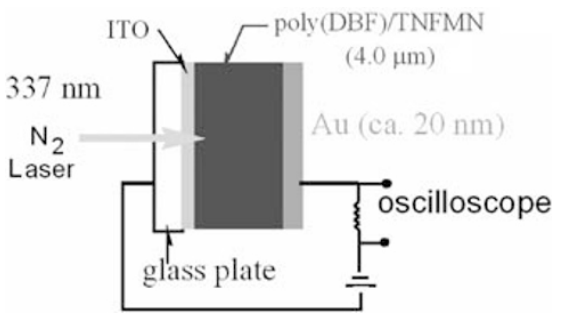

Figure 21 Schematic illustration of a sandwich-type cell for TOF experiments.

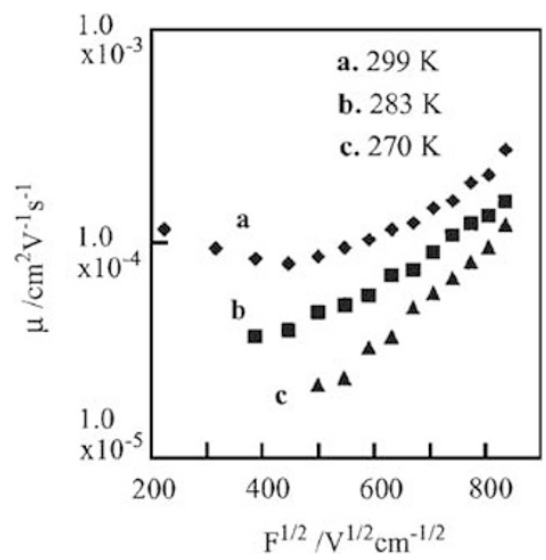

Figure 22 Hole drift mobility of poly(DBF) film $(4 \mu \mathrm{m})$ (a) at $299 \mathrm{~K}$, (b) at $283 \mathrm{~K}$, and (c) at $270 \mathrm{~K}$. Reproduced with permission from Nakano et al. ${ }^{18}$ Copyright (2004) The Chemical Society of Japan.

polymers so far studied have a long electronic conjugation system in the main chain, a few vinyl polymers with no main-chain conjugation indicate intriguing electronic properties as represented by poly $(\mathrm{N}$ vinylcarbazole) (poly $(\mathrm{NVCz})$ ), which finds practical applications on the basis of its photoconductivity. ${ }^{73,74}$ In this section, the electronic properties of poly(DBF) are discussed. ${ }^{18}$

Hole drift mobility was measured by a time-of-flight method ${ }^{75-77}$ using a cast film of the polymer. Poly(DBF) prepared by anionic polymerization using 9-FlLi in THF at $-78^{\circ} \mathrm{C}\left(M_{\mathrm{n}}=1070, M_{\mathrm{w}} /\right.$ $M_{\mathrm{n}}=1.38$, size exclusion chromatography using oligo(DBF)s as the standard sample) $(20 \mathrm{mg})$ and 2,4,7-trinitrofluorenylidene-9-malononitrile $(1.0 \mathrm{mg})$ as an acceptor was dissolved in chloroform $(1.0 \mathrm{ml})$, and the solution was cast on an indium-tin oxide glass plate and slowly dried under air to afford a thin film (thickness $5 \mu \mathrm{m}$ ). A circular Au electrode (thickness $20 \mathrm{~nm}$, diameter $5 \mathrm{~mm}$ ) was vacuum deposited onto the film to produce a sandwich-type cell for drift mobility measurement (Figure 21).

Charge drift mobility $(\mu)$ was estimated by time-of-flight transient photocurrent measurement under vacuum under $\mathrm{N}_{2}$ pulse laser irradiation $(337 \mathrm{~nm}$, pulse duration $3 \mathrm{~ns}, 50 \mu \mathrm{J})$. The value of $\mu$ was calculated according to $\mu=d /\left(t_{\tau} \cdot F\right)\left(\mathrm{cm}^{2} \mathrm{~V}^{-1} \mathrm{~s}^{-1}\right)$, where $d$ is the film thickness, $t_{\tau}$ is the transit time determined by the time-of-flight experiment, and $F$ is the field strength. By switching polarity in the measurement, it was confirmed that holes mediate the charge drift in the present systems. Figure 22 indicates the $\mu$ values at different $F$ values and different temperatures. Overall, a higher field strength led to a higher drift mobility; however, a reverse relationship was observed in the field strength range below $2 \times 10^{5} \mathrm{~V} \mathrm{~cm}^{-1}$. In this range, holes may transport in a different path from that predominantly used at the 
higher field strength, suggesting that the polymer sample is somewhat heterogeneous in terms of molecular structure and/or intermolecular arrangement. Hole drift mobility was higher at a higher temperature at all field strengths, indicating that the charge drift is thermally activated.

The observed charge drift mobility was as high as $2.7 \times 10^{-4} \mathrm{~cm}^{2} \mathrm{~V}^{-1} \mathrm{~s}^{-1}$ at $299 \mathrm{~K}$ at $F=7 \times 10^{5} \mathrm{~V} \mathrm{~cm}^{-1}$. This value is higher by the order of $10^{3}$ than that for other side-chain aromatic vinyl polymers including poly $(\mathrm{NVCz})$ and poly(1-vinylpyrene) $\left(10^{-7} \mathrm{~cm}^{2} \mathrm{~V}^{-1} \mathrm{~s}^{-1}\right.$ order $),{ }^{78}$ and is the highest so far reported for a vinyl polymer, although mobility values higher than $10^{-2} \mathrm{~cm}^{2} \mathrm{~V}^{-1} \mathrm{~s}^{-1}$ have been reported for some other types of organic polymers. ${ }^{79-81}$ The hole drift mobility of poly(DBF) is even higher than that of main-chain conjugating poly( $p$-phenylenevinylene) $\left(1 \times 10^{-5} \mathrm{~cm}^{2} \mathrm{~V}^{-1} \mathrm{~s}^{-1}\right),{ }^{82}$ is comparable to that of poly(methylphenylsilane) $\left(1 \times 10^{-4} \mathrm{~cm}^{2} \mathrm{~V}^{-1} \mathrm{~s}^{-1}\right),{ }^{83}$ and is slightly lower than Se $\left(10^{-4} \mathrm{~cm}^{2} \mathrm{~V}^{-1} \mathrm{~s}^{-1}\right.$ order $),{ }^{73}$ an inorganic semiconductor.

In the film sample, both intramolecular and intermolecular charge transfers may take place, and the observed charge mobility will mainly reflect the slower process. Because the poly(DBF) chains used in this study seem to have disordered intermolecular alignments on the basis of the almost linear field dependences of mobility in the higher field ranges, the major limiting step of the drift mobility will be the intermolecular charge transfer. The disordered structure was supported by the fact that the film did not show birefringence in the polarizing microscopy observation. In addition, the poly(DBF) sample used here did not show a clear melting point in DSC analysis, further supporting that the chains do not have an ordered alignment.

From the conclusion of the disordered system, it may be assumed that intramolecular charge transfer is faster than the bulk mobility characterized by $\mu=2.7 \times 10^{-4} \mathrm{~cm}^{2} \mathrm{~V}^{-1} \mathrm{~s}^{-1}$. This idea is supported by cyclic voltammetry measurements of poly(DBF) in which the oxidation potential for poly(DBF) was significantly lower than that for fluorene, a model of monomeric side chain as discussed in the preceding section. This indicates that a hole may be readily delocalized over the $\pi$-stacked fluorene groups in the side chain, leading to fast intramolecular charge transfer. The ordered molecular structure of the $\pi$-stacked poly(DBF) may act as a charge transport pathway.

From data in Figure 22, field-dependent activation energies for the charge transport were calculated to be $0.22 \mathrm{eV}$ at $F=7.0 \times 10^{5} \mathrm{Vcm}^{-1}$. This value is much smaller than that of poly $(\mathrm{NVCz})(0.4-0.7 \mathrm{eV})^{73}$ and is comparable to that of poly(methylphenylsilane) $(0.24 \mathrm{eV}){ }^{83}$ For poly $(\mathrm{NVCz})$, locally $\pi$-stacked chromophores are trap sites for charge drift, ${ }^{84,85}$ and the activation energy corresponds to the thermal hopping-up of charges from the $\pi$-stacked trap sites. ${ }^{73}$ The smaller activation energies of poly(DBF) support the fact that the hole transport mechanism in poly(DBF) is completely different from that in poly $(\mathrm{NVCz})$. Although comparisons between poly $(\mathrm{DBF})$ and other vinyl polymers with $\pi$-stacked structures should be more appropriate, no such polymer other than poly(DBF) is known so far. Poly(NVCz) was chosen to be a reference compound in this context as a vinyl polymer showing a relatively high charge mobility.

To summarize this section, the charge mobility of the poly(DBF) film was as high as some main-chain conjugating polymers. In addition, fast intramolecular charge transport was suggested to take place through the stacked $\pi$-electron systems. Charge transport through regularly stacked heteroaromatic systems has been proposed for DNAs in which the stacked systems serve as a ' $\pi$-way, ${ }^{86-89}$ although there is controversy as to whether they really conduct. ${ }^{90-92}$ Poly(DBF) may be recognized as a new, synthetic ' $\pi$-way' molecule.
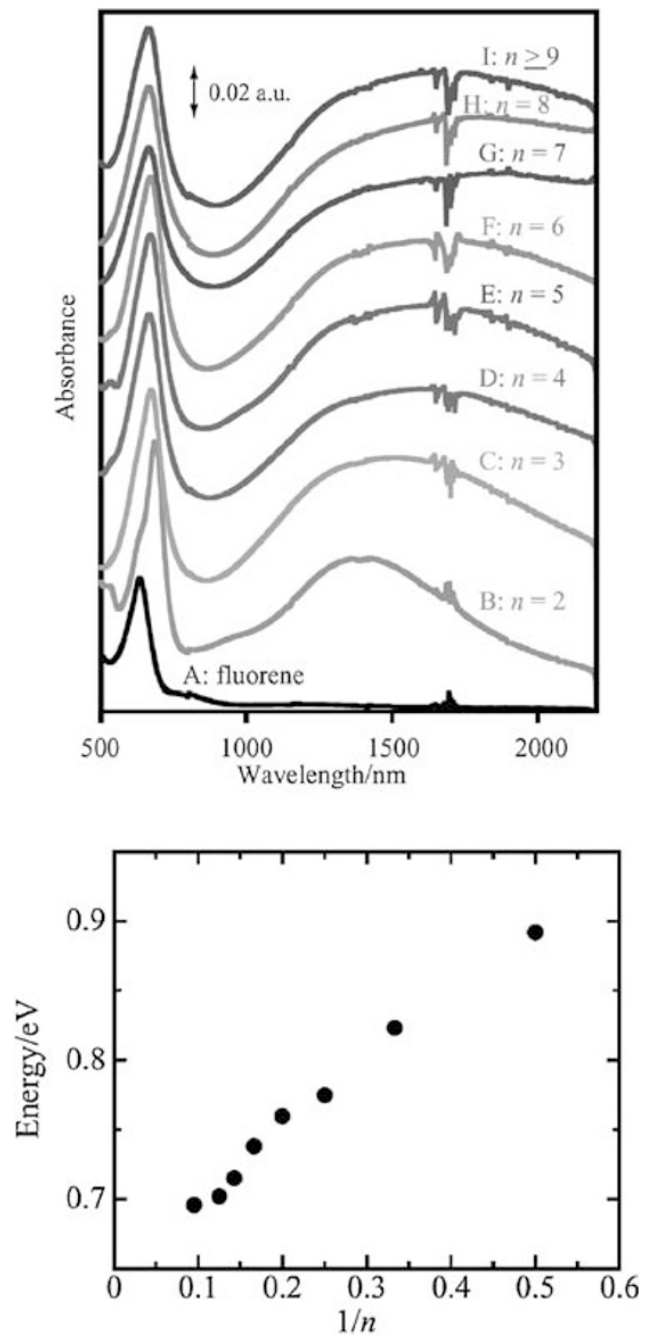

Figure 23 (Top) NIR absorption spectra of fluorene (A), DBF oligomers $f$ $n=2-8(\mathrm{~B}-\mathrm{H})$, and a polymeric mixture $\left(n \geqslant 9, M_{n}=1890\right)(\mathrm{I})$ treated with $\mathrm{SbCl}_{5}$ in $\mathrm{CH}_{2} \mathrm{Cl}_{2}$ at room temperature. Solvent spectra were subtracted. Absorbance was normalized to a constant concentration of oligomer at [oligomer] $=1.0 \times 10^{-5} \mathrm{M}$. Measurement conditions: $[D B F$ unit or fluorene $]=0.59-1.6 \times 10^{-4} \mathrm{M} ;\left[\mathrm{SbCl}_{5}\right]=0.66-1.3 \times 10^{-3} \mathrm{M}$. (Bottom) $\mathrm{CR}$ band peak-top energy plotted against oligomer chain length $(1 / n)$. Reproduced with permission from Nakano et al. ${ }^{93}$ Copyright (2008) The Chemical Society of Japan.

In addition to the $\mathrm{CV}$ and time-of-flight experiments, charge delocalization over the stacked fluorene side chains in poly(DBF) was directly observed by the NIR absorption spectra of oxidized species generated by reaction with $\mathrm{SbCl}_{5}$ (Figure 23). ${ }^{93}$ Although oxidized fluorene as a monomeric unit model showed only absorption bands based on radial cation species around $650 \mathrm{~nm}, \pi$-stacked poly(DBF) with various DP showed a broad hole resonance band in the NIR region. Further, the peak top energy decreased with an increase in DP (Figure 23, bottom). These results strongly suggest that a hole chemically injected into poly(DBF) delocalizes through the $\pi$-stacked side-chain chromophores. A theoretical analysis on charge delocalization in a $\pi$-stacked DBF dimer has also been conducted. ${ }^{94}$ The analysis according to a tight-binding band model indicated that transfer integral $(t)$ between two stacked fluorene moieties was 0.2$0.3 \mathrm{eV}$, which was much larger than the value estimated for pentacene 


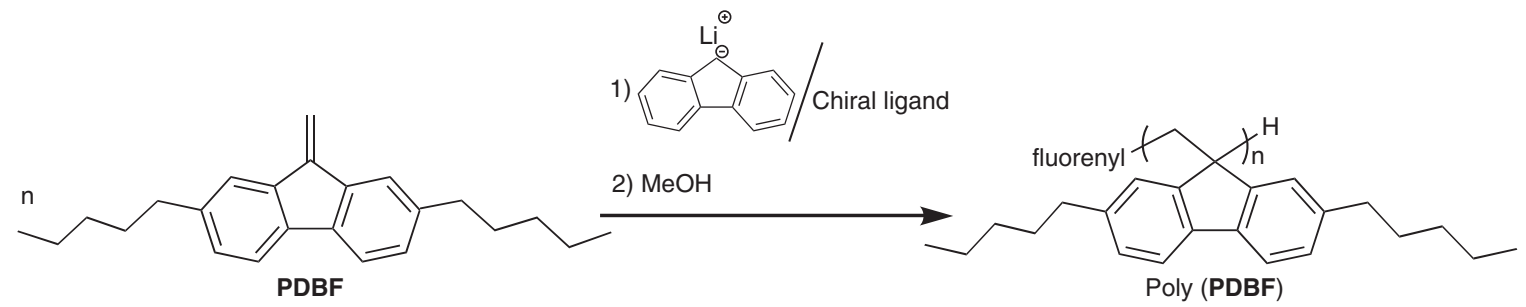

Chiral ligands:<smiles>COC(=CN(C)C)[C@H](CN(C)C)OC</smiles>

(+)-DDB<smiles>CO[C@@H](CN(C)C)[C@@H](CN(C)C)OC</smiles>

$(-)-D D B$

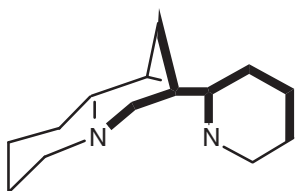

$(-)-S p$

Figure 24 Asymmetric anionic polymerization of PDBF.

(less than $0.1 \mathrm{eV}$ ). This implies that poly(DBF) has a larger band width compared with pentacene and therefore it may potentially be an excellent charge transport material.

\section{CHIRALITY OF $\pi$-STACKED POLYMERS}

As noted earlier, the main chain of poly(DBF) is not completely zigzag but is slightly twisted in a single direction as proved by X-ray crystal analysis. In solution, it is expected that poly(DBF)'s twist (helix) exists in an equimolar amount mixture of right-handed and left-handed ones, probably in a dynamic equilibrium. In our studies, the helix was made single-handed by introducing a chiral terminal group to the poly(DBF) chain ${ }^{21}$ and by polymerizing 2,7 -di- $n$-pentyldibenzofulvene $(\mathrm{PDBF})$, a monomer having pentyl groups at the 2- and 7positions of DBF, which would prevent helix reversal of the main chain by steric repulsion, using optically active anionic initiators. ${ }^{19}$

The former method was conducted by polymerization DBF using a reaction product between (-)-menthol and $\mathrm{KH}$ as an anionic initiator. The resulting polymer indicated intense circular dichroism (CD) spectra in the wavelength regions where fluorene chromophore absorbs light, indicating that single-handed helicity was induced to the main chain by the terminal menthoxy group. The absolute configuration of the preferred helical sense was determined to be left by semiempirical spectral calculations. Moreover, the CD intensity of poly(DBF) having the terminal menthyl group largely varied depending on measurement temperature, whereas the spectral pattern was unchanged. These results suggest that the helix of poly(DBF) is rather dynamic.

The latter method was effected by asymmetric anionic polymerization of PDBF using the complexes of 9-FlLi with (-)-sparteine (Sp) and (+)- and (-)-1,4-bis(dimethylamino)-2,3-dimethoxybutane (DDB) in toluene or using $n$-BuLi in THF under $\mathrm{N}_{2}$ atmosphere at $-78^{\circ} \mathrm{C}$ (Figure 24). The conditions and results of polymerization are summarized in Table 5. Chiral complexes have been effectively used in helix-inducing polymerization of methacrylates. ${ }^{95,96}$ The polymers were partially insoluble in THF and chloroform. The THF-insoluble part seems to have the same chemical structure as that of the THFsoluble part based on infrared spectra; the insoluble part probably has a higher molecular weight as in the case of poly(DBF) with no substituent.

The introduction of two pentyl groups per fluorene unit does not seem to affect the formation of $\pi$-stacked conformation. Similar to poly(DBF) without substituents, THF-soluble poly(PDBF)s showed
Table 5 Anionic polymerization of 2,7-di-n-pentyldibenzofulvene at $-78{ }^{\circ}{ }^{a}$

\begin{tabular}{|c|c|c|c|c|c|c|c|}
\hline \multirow{2}{*}{\multicolumn{2}{|c|}{ Run Initiator }} & \multicolumn{6}{|c|}{ THF-insol. ${ }^{\mathrm{C}}$ part- } \\
\hline & & \multicolumn{2}{|c|}{ Solvent Convertion ${ }^{\mathrm{b}}(\%)$} & \multirow{2}{*}{$\begin{array}{c}\text { Yield (\%) } \\
3\end{array}$} & \multirow{2}{*}{$\begin{array}{c}\text { Yield (\%) } \\
24\end{array}$} & \multirow{2}{*}{$\frac{\mathrm{M}_{n}^{\mathrm{d}}}{5290}$} & \multirow{2}{*}{$\frac{\mathrm{M}_{w} \mathrm{M}_{n}^{\mathrm{d}}}{1.03}$} \\
\hline 1 & (+)-DDB-FILi & Toluene & 40 & & & & \\
\hline 2 & (-)-DDB-FILi & i Toluene & 50 & 2 & 49 & 5710 & 1.16 \\
\hline 3 & Sp-FILi & Toluene & 73 & 21 & 50 & 5950 & 1.05 \\
\hline 4 & $n$-BuLi & THF & $>99$ & Trace & 84 & 4750 & 1.20 \\
\hline
\end{tabular}

aConditions: time $=24 \mathrm{~h}$; monomer amount $=1.00-1.02 \mathrm{mmol}$; [monomer] $=0.20-0.21 \mathrm{~m}$; [ligand $] /[\mathrm{Li}]=1.2 ;[\text { monomer }]_{0} /[\mathrm{RLi}]_{0}=20$.

betermined by ${ }^{1} \mathrm{H}$ NMR analysis of the reaction mixture.

'The quenched reaction mixture was first separated into $\mathrm{MeOH}$-soluble and -insoblule parts, and the insoluble part was then extracted using tetrahydrofuran (THF).

dDetermined by size-exclusion chromatography using a Viscotek TDA300 detector (Viscotek, Determined by size-exclusion chromatography using a Viscotek TDA300 detector (Visco
Houston, TX, USA), which collects right angle laser light scattering, viscosity and RI Houston, TX, USA), which collects right angle laser light scattering, viscosity and RI
information. Reproduced from Nakano et al. ${ }^{19}$. Copyright (2004) The Royal Society of Chemistry.
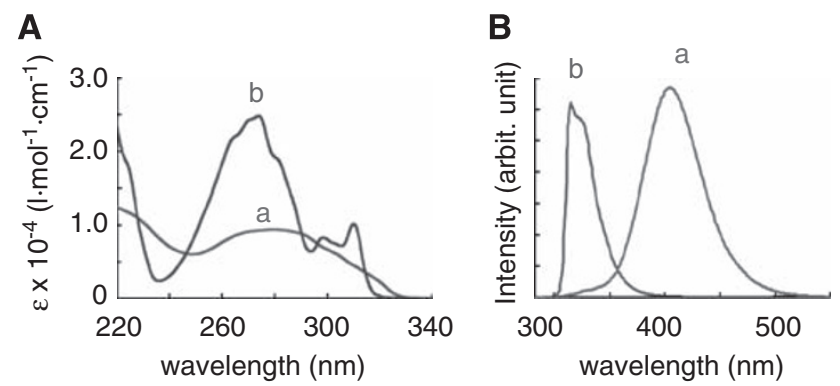

Figure 25 Absorption (A) and emission (B) spectra of poly(PDBF)s prepared using (-)-Sp-FILi (run 3 in Table 6) (a) and 2,7-di-n-pentylfluornene (b), a model of monomeric unit in THF at room temperature. Conditions: concentration $1.8 \times 10^{-5} \mathrm{M}$ (a), $1.7 \times 10^{-5} \mathrm{M}$ (per choromophore) (b); cell length $0.1 \mathrm{~mm}$ (absorption), $10 \mathrm{~mm}$ (emission); $\lambda_{\text {ex }}$ for emission $282 \mathrm{~nm}$. Reproduced with permission from Nakano et al. ${ }^{19}$ Copyright (2004) The Royal Society of Chemistry.

remarkable hypochromism in absorption spectra and exclusive excimer emission in fluorescent spectra as shown in Figure 25.

Although chiral ligands were used for anionic polymerization, the THF-soluble PDBF polymers prepared using the optically active initiators did not show detectable CD absorption bands or optical 


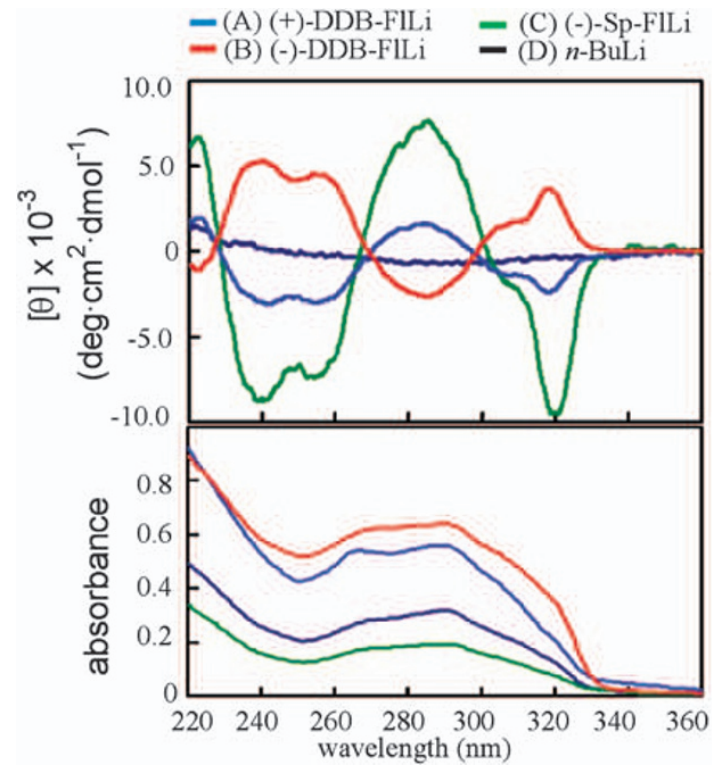

Figure $26 \mathrm{CD}$ (top) and absorption (bottom) spectra of THF-soluble poly(PDBF)s prepared using (+)-DDB-FILi $\left(M_{\mathrm{n}=5290}, M_{\mathrm{w}} / M_{\mathrm{n}}=1.03\right.$ ) (run 1 in Table 6) (A), (-)-DDB-FILi $\left(M_{\mathrm{n}}=5710, M_{\mathrm{w}} / M_{\mathrm{n}}=1.16\right)$ (run 2 in Table 5) (B), (-)-Sp-FILi $\left(M_{\mathrm{n}}=5950, M_{\mathrm{w}} / M_{\mathrm{n}}=1.05\right)$ (run 3 in Table 5) (C), and $n$-BuLi $\left(M_{\mathrm{n}}=4750, M_{\mathrm{w}} / M_{\mathrm{n}}=1.20\right)$ (run 4 in Table 5) (D) measured using a JASCO J-820 spectrometer (JASCO, Tokyo, Japan). Concentration of film samples for molar elipticity calculation was determined by comparing absorbance at $290 \mathrm{~nm}$ of a film with that of a solution in THF (concentration $1.10 \times 10^{-2} \mathrm{M}$, cell length $0.1 \mathrm{~mm}$, absorbance at $290 \mathrm{~nm} 0.983$ ). Thickness of film B was $0.10-0.16 \mu \mathrm{m}$ as measured using a Keyence VK9500 Laser microscope (Keyence, Osaka, Japan). Reproduced with permission from Nakano et al. ${ }^{19}$ Copyright (2004) The Royal Society of Chemistry.

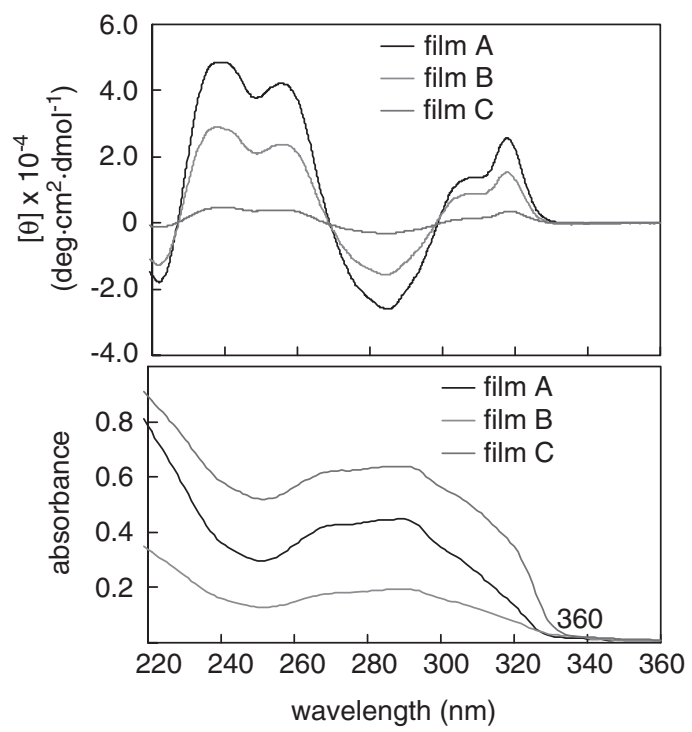

Figure $27 \mathrm{CD}$ intensity variation of films prepared from poly(PDBF) synthesized using (-)-DDB-FILi (run 2 in Table 5: (A) a film with a smooth surface, (B) a film with a modestly smooth surface (smoothness was between $\mathrm{A}$ and $\mathrm{C}$ ), and (C) a film with a wrinkled surface. Reproduced with permission from Nakano et al. ${ }^{19}$ Copyright (2004) The Royal Society of Chemistry.

rotation in a THF solution. No CD absorption was observed in solution even at $-50{ }^{\circ} \mathrm{C}$. However, thin films cast on a quartz plate from a hexane solution of polymers (concentration $3 \mathrm{gl}^{-1}$ ) showed intense CD bands (Figures 26a-c). The spectra in the film of polymers obtained using (+)-DDB-FlLi and (-)-DDB-FlLi were almost mirror images in spectral pattern (A and $\mathbf{B})$. The polymer obtained using (-)-Sp-FlLi showed an intense spectrum with a spectral pattern similar to that of the polymer obtained with (+)-DDB-FlLi. The polymer obtained by polymerization with achiral $n$-BuLi did not show CD absorptions in film (D). In addition, the film of the polymer synthesized using (-)-DDB-FlLi (run 2 in Table 5) showed optical rotatory dispersion in the wavelength range shorter than $330 \mathrm{~nm}$ : $[\alpha]_{295}-25^{\circ}$.

Spectral intensity varied from film to film prepared in repeated experiments. As an example, $\mathrm{CD}$ and absorption spectra of the three film samples prepared using poly(PDBF) from run 2 in Table 5 are shown in Figure 27. The films differed in thickness and roughness of the surface. A smoother film tended to show larger $\mathrm{CD}$ band intensities. Film surface morphologies of samples in Figures 27a and $\mathrm{c}$ are shown in Figures 28a and b, respectively. In most cases, the film surface showed a relatively regular, wrinkled pattern as shown in Figure 28b. Such macroscopic morphologies might have a close connection to the molecular structure (conformation) of the polymer in the film.

However, for a certain polymer, the signs and patterns of $\mathrm{CD}$ spectra were unchanged. In addition, changing the direction and orientation of the film sample did not significantly affect the spectral intensity and pattern. Furthermore, the films did not show birefringence in polarized optical microscopy analysis. These observations rule out the possibility that the CD spectra are due to linear dichroism based on film anisotropy and support that the film spectra reflect molecular chirality. CD absorptions similar to those indicated in film were also observed for a decalin suspension of THF-insoluble polymer (fine powder ground with a mortar) synthesized using (-)-Sp-FlLi. This further supports that the CD spectra in film (Figure 26) do not arise from sample anisotropy.

As described earlier, DBF oligomers have been shown to have a $\pi$-stacked, single-handed helical conformation in crystal. A $\pi$-stacked structure was also indicated for poly(PDBF) by remarkable hypochromicity in absorption and exclusive dimer emission in fluorescence spectra (Figure 25). Therefore, it can be reasonably assumed that the CD absorptions observed in this study are based on a helical conformation of poly(PDBF) with excess single handedness. Because the polymers showing clear CD bands in film did not show chiroptical properties in solution, molecular aggregation may amplify and stabilize the single-handed helical conformation induced by asymmetric polymerization possibly because of intermolecular cooperative effects ${ }^{97}$ in the solid state. Atomic force microscopic analyses support this assumption (Figure 29). The samples were prepared by dropping a dilute THF solution $\left(1 \times 10^{-4} \mathrm{M}\right.$ per residue $)$ onto an untreated mica surface. The polymer prepared using (-)-Sp-FlLi formed long, chain-like aggregates. On the other hand, the polymer prepared by achiral n-BuLi did not from such aggregates but simple dots. These results suggest that single-handed helical chains in the solid state may tend to form large helical bundles, whereas racemic helices do not.

To obtain information on the poly(PDBF) molecular structure, $\mathrm{MD}$ simulations were perfomed for a PDBF 20-mer model created on the basis of the DBF oligomer conformation in crystal (Figure 7) under a constant NVT condition with a COMPASS force field at $300 \mathrm{~K}$ for 8.6 ns. The simulation afforded the structure shown in Figure 30 in which the neighboring fluorene moieties stack on top of each other in a chiral, slightly twisted arrangement. The entire chain formed a relatively long-pitched helical structure in simulation. Hence, the local twist and the helix may contribute to the CD spectra. 

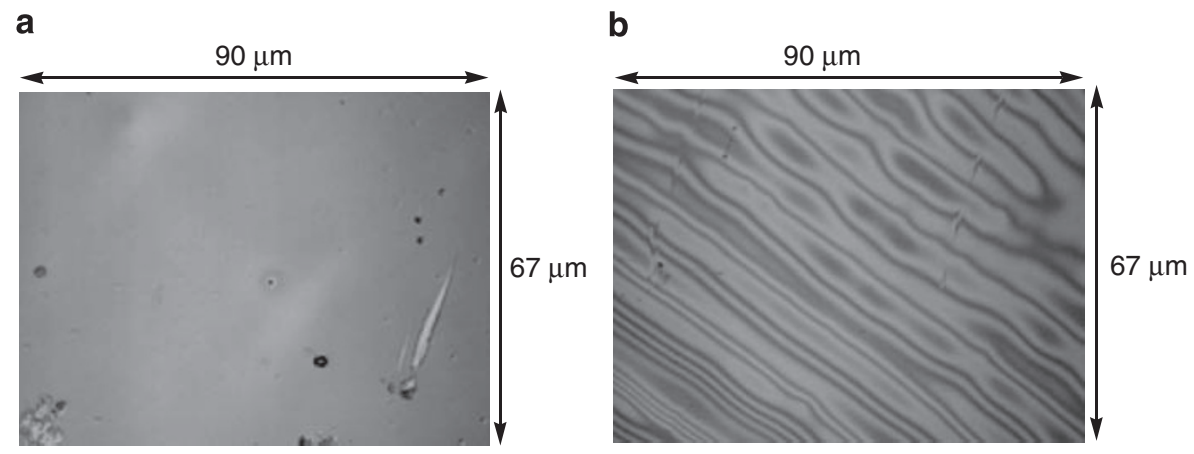

Figure 28 Surface pictures of films made from poly(PDBF) synthesized using (-)-DDB-FILi (run 2 in Table 5): (a) a film with a smooth surface and (b) a film with a wrinkled surface (wrinkle height 0.3-0.6 $\mu \mathrm{m}$ ). Films A and B correspond to spectra A and C in Figure 27, respectively. This analysis was preformed using a Keyence VK-9500 Laser microscope (Laser wavelength $408 \mathrm{~nm}$ ). Reproduced with permission from Nakano et al. ${ }^{19}$ Copyright (2004) The Royal Society of Chemistry.

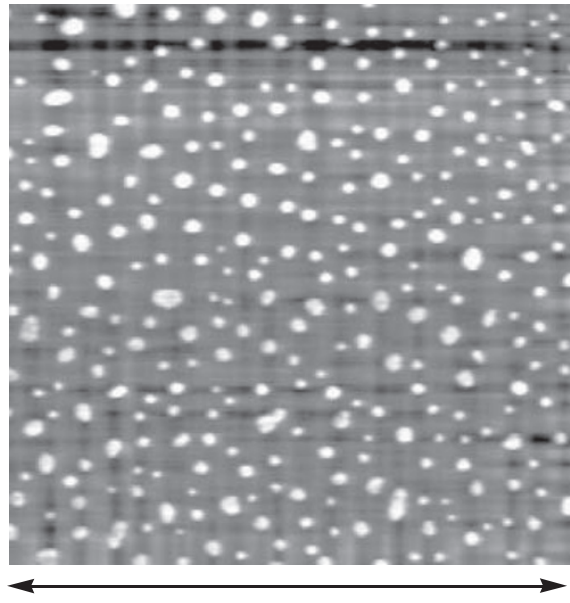

$4 \mu \mathrm{m}$

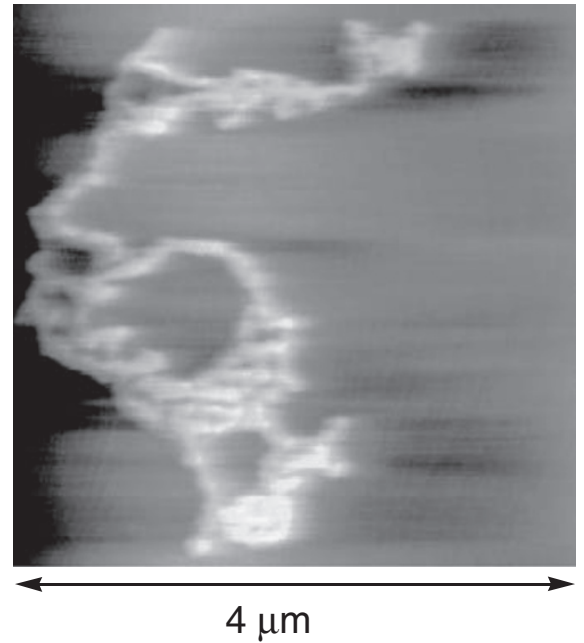

$4 \mu \mathrm{m}$

Figure 29 Atomic force microscopic images (topographic image) of poly(PDBF)s synthesized using $n$-BuLi (left) and (-)-Sp-FILi (right) (runs 4 and 3 , respectively, in Table 5) (Seiko Instruments SPA400-SPI3800N, DFM mode; Chiba, Japan). Reproduced with permission from Nakano et al. ${ }^{19}$ Copyright (2004) The Royal Society of Chemistry.
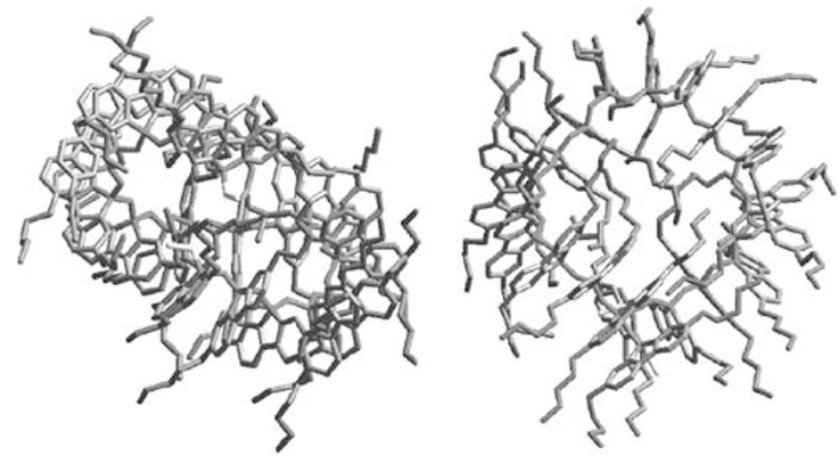

Figure 30 The conformation of a PDBF 20-mer having terminal ethyl groups generated through MD simulation (NVT, $300 \mathrm{~K}, 8 \mathrm{~ns}$ ): side and top views. The main chain is shown in red, fluorene moieties in gray, pentyl groups in light blue and terminal ethyl groups in yellow. Reproduced with permission from Nakano et al. ${ }^{19}$ Copyright (2004) The Royal Society of Chemistry. A full colour version of this figure is available at the Polymer Journal online.

The chiral conformation contributing to the CD spectra is constructed during polymerization by the effect of chiral ligands. The CD spectra and chiral conformation do not arise from residual chiral ligand, which may be contained in polymer samples in a small quantity. The isolated polymers were washed with methanol to remove the ligand residue, and the ligand residue contents in methanol-insoluble polymers were less than $0.01 \mathrm{~mol} \%$ (per monomeric residue) as determined by ${ }^{1} \mathrm{H}$ NMR. It was confirmed that a film made from a mixture of the achiral polymer synthesized using $\mathrm{n}$-BuLi and $0.01 \mathrm{~mol} \%$ of (-)-Sp did not show clear CD. This rules out the possibility that residual ligand is responsible for the $\mathrm{CD}$ spectra in Figure 26.

The poly(PDBF)s prepared using chiral initiators have a chiral conformation in solution, although their chiroptical properties are under detectable level, that is, they are cryptochiral. ${ }^{98}$ To test conformational stability in solution, THF-soluble polymer synthesized using (-)-Sp-FlLi (run 3 in Table 5) was heated in a toluene solution at $110{ }^{\circ} \mathrm{C}$ for $16 \mathrm{~h}$. A film made from the polymer after heat treatment still showed intense $\mathrm{CD}$ bands, indicating that the conformation induced in polymerization was stable in a solution under these conditions.

Synthetic polymers with conformational chirality have become a research field of widespread interest in recent years, and a wide range of polymers with conformational chirality have been synthesized from various types of monomers including vinyl monomers. ${ }^{99-111}$ The 
existing examples of optically active vinyl polymers with conformational chirality include isotactic, helical polyolefins bearing asymmetric side chains, ${ }^{106-108}$ and isotactic, helical polymethacrylates bearing bulky, achiral side chains. ${ }^{95,96,99,100,103}$ These polymers have stereocenters in the main and/or side chains. Optically active poly(PDBS) is the first vinyl polymer with conformational chirality bearing no stereocenters in the main and side chains, the chiroptical properties of which arise only from a chiral conformation.

\section{CONCLUSIONS}

DBF has a relatively simple chemical structure based on fluorene and may not seem special at a glance. However, it exhibits characteristic polymerization behaviors including high reactivity and the stereochemical features that are not known for other simple vinyl monomers such as styrene, vinylfluorenes or vinylcarbazoles. The $\pi$-stacked structure of poly(DBF) is not only unique as a conformation of a vinyl polymer but also has practical importance in the fact that it can mediate charge transport. In addition, the chiral conformation of poly(PDBF) suggests that poly(DBF) and its family may find applications in fields such chiral recognition and nonlinear optical materials.

$\pi$-Stacked structures may not have been generally recognized as an important category of structures by polymer chemists so far. Even a DNA duplex is generally classified as a helical polymer, not a $\pi$-stacked polymer, in the field of structural polymers. This is because there have been only a limited number of $\pi$-stacked polymers the structures of which were clearly identified, and also because their syntheses are not necessarily simple and their practical properties have not been well exploited. However, poly(DBF) and its derivatives can be readily synthesized by simple vinyl polymerization; their structures are unambiguously identified and they show intriguing properties as described in this review. A $\pi$-stacked polymer structure may be regarded as one of the basic and important structural motifs of synthetic macromolecules.

\section{ACKNOWLEDGEMENTS}

I thank all co-workers and collaborators for their great contributions reported in this review. Financial support from the Japan Science and Technology Agency and from Grant-in-Aid and the Global COE Program (Project No. B01: Catalysis as the Basis for Innovation in Materials Science) from the Ministry of Education, Culture, Sports, Science, and Technology, Japan is gratefully appreciated.

1 Ferraris, J., Cowan, D. O., Walatka, V. \& Perlstein, J. H. Electron transfer in a new highly conducting donor-acceptor complex. J. Am. Chem. Soc. 95, 948-949 (1973).

2 Jerome, D., Mazaud, A., Ribault, M. \& Bechgaard, K. Superconductivity in a synthetic organic conductor (TMTSF) ${ }_{2} \mathrm{PF}_{6}$. J. Phys. Lett. 41, 95-98 (1980).

3 Watson, J. D. \& Crick, F. H. Molecular structure of nucleic acids; a structure for deoxyribose nucleic acid. Nature 171, 737-738 (1953).

4 Nelson, J. C., Saven, J. G., Moore, J. S. \& Wolynes, P. G. Solvophobically driven folding of nonbiological oligomers. Science 277, 1793-1796 (1997).

5 Lokey, R. S. \& Iverson, B. L. Synthetic molecules that fold into a pleated secondary structure in solution. Nature 375, 303-305 (1995).

6 Nguyen, J. Q. \& Iverson, B. L. An amphiphilic folding molecule that undergoes an irreversible conformational change. J. Am. Chem. Soc. 121, 2639-2640 (1999).

7 Ramkumar, S. G. \& Ramakrishnan, S. Understanding the folding process of synthetic polymers by small-molecule folding agents. J. Chem. Sci. 120, 187-194 (2008).

8 Wang, W., Li, L.- S., Helms, G., Zhou, H.- H. \& Li, A. D. Q. To fold or to assemble? J. Am. Chem. Soc. 125, 1120-1121 (2003).

9 Han, J. J., Shaller, A. D., Wang, W. \& Li, A. D. Q. Architecturally diverse nanostructured foldamers reveal insightful photoinduced single-molecule dynamics. J. Am. Chem. Soc. 130, 6974-6982 (2008).

10 Mizogami, S. \& Yoshimura, S. Synthesis of a new polyconjugated system: polycyclophane. J. Chem. Soc. Chem. Commun. 1985, 427-428 (1985).

11 Mizogami, S. \& Yoshimura, S. Synthesis of a new crystalline polymer: polymetacyclophane. J. Chem. Soc., Chem. Commun. 1985, 1736-1738 (1985).
12 Morisaki, Y. \& Chujo, Y. Through-space conjugated polymers based on cyclophanes. Angew. Chem. Int. Ed. 45, 6430-6437 (2006).

13 Cappelli, A., Pericot Mohr, G. P., Anzini, M., Vomero, S., Donati, A., Casolaro, M., Mendichi, R., Giorgi, G. \& Makovec, F. Synthesis and characterization of a new benzofulvene polymer showing a thermoreversible polymerization behavior. J. Org. Chem. 68, 9473-9476 (2003).

14 Cappelli, A., Galeazzi, S., Giuliani, G., Anzini, M., Aggravi, M., Donati, A., Zetta, L., Boccia, A. C., Mendichi, R., Giorgi, G., Paccagnini, E. \& Vomero, S. Anionic polymerization of a benzofulvene monomer leading to a thermoreversible $\pi$-stacked polymer. Studies in macromolecular and aggregate structure. Macromolecules 41, 2324-2334 (2008)

15 Nakano, T., Takewaki, K., Yade, T. \& Okamoto, Y. Dibenzofulvene, a 1,1-diphenylethylene analogue, gives a $\pi$-stacked polymer by anionic, free-radical, and cationic catalysts. J. Am. Chem. Soc. 123, 9182-9183 (2001).

16 Nakano, T. \& Yade, T. Synthesis, structure, and photophysical and electrochemical properties of a $\pi$-stacked polymer. J. Am. Chem. Soc. 125, 15474-15484 (2003).

17 Nakano, T., Yade, T., Fukuda, Y., Yamaguchi, T. \& Okumura, S. Free-radical polymerization of dibenzofulvene leading to a $\pi$-stacked polymer: structure and properties of the polymer and proposed reaction mechanism. Macromolecules 38, 8140-8148 (2005).

18 Nakano, T., Nakagawa, O., Yade, T. \& Okamoto, Y. Solid-state polymerization of dibenzofulvene leading to a copolymer with oxygen. Macromolecules 36, 1433-1435 (2003).

19 Nakano, T., Yade, T., Yokoyama, M. \& Nagayama, N. Charge transport in a $\pi$-stacked Poly(dibenzofulvene) film. Chem. Lett. 33, 296-297 (2004).

20 Nakano, T., Nakagawa, O., Tsuji, M., Tanikawa, M., Yade, T. \& Okamoto, Y. Poly(2,7-di$n$-pentyldibenzofulvene) showing chiroptical properties in the solid state based purely on a chiral conformation. Chem. Commun. 144-145 (2004).

21 Nakano, T., Yade, T., Ishizawa, H., Nakagawa, O. \& Okamoto, Y. Synthesis of polydibenzofulvene having stacked $\pi$-electron systems, a new potential polymer for photonics and electronics. ACS Polym. Prepr. 43, 609 (2002).

22 Nakano, T., Tanikawa, M., Nakagawa, O., Yade, T. \& Sakamoto, T. Synthesis and structure of an optically active $\pi$-stacked Poly(dibenzofulvene) bearing chiral terminal group. J. Polym. Sci., Part A: Polym. Chem. 47, 239-246 (2009).

23 Morisaki, Y. \& Chujo, Y. Construction of benzene ring-layered ppolymers. Tetrahedron Lett. 46, 2533-2537 (2005).

24 Morisaki, Y., Murakami, T., Sawamura, T. \& Chujo, Y. [2.2]Paracyclophane-layered polymers end-capped with fluorescence quenchers. Macromolecules 42, 3656-3660 (2009).

25 Rathore, R., Abdelwahed, S. H. \& Guzei, I. A. Synthesis, structure, and evaluation of the effect of multiple stacking on the electron-donor properties of $\pi$-stacked polyfluorenes. J. Am. Chem. Soc. 125, 8712-8713 (2003).

26 Greenhow, E. J., McNeil, D. \& White, E. N. Fluorene. II. The dehydration of 9-hydroxyethylfluorenes. J. Chem. Soc. 1952, 986-992 (1952).

27 More O'Ferrall, R. A. \& Slae, S. Reaction of 9-fluorenylmethanol with base: a carbanion mechanism of $\beta$-elimination. J. Chem. Soc., Chem. Commun. 486-487 (1969).

28 Wieland, H. \& Probst, O. Fluorene series. IV. Several reactions of biphenylenethylene. Justus Liebigs Ann. Chem. 530, 274-290 (1937).

29 Evans, A. G. \& George, D. B. The catalytic action of anionic catalysts. I. The interaction of butyllithium with 1,1-diphenylethylene. J. Chem. Soc. 1961, 4653-4659 (1961).

30 Evans, A. G. \& George, D. B. The catalytic action of anionic catalysts. II. The products of reaction of butyllithium with 1,1-diphenylethylene in benzene. J. Chem. Soc. 1962, 141-146 (1962)

31 Yuki, H., Hotta, J., Okamoto, Y. \& Murahashi, S. Anionic copolymerization of styrene and 1,1-diphenylethylene. Bull. Chem. Soc. Jpn. 40, 2659-2663 (1967).

32 Richards, D. H. \& Scilly, N. F. The synthesis of regular copolymers of 1,1-diphenylethylene. J. Polym. Sci., Part B, Polym. Lett. 7, 99-101 (1969).

33 Dewar, M. S. J., Zoebisch, E. G., Healy, E. F. \& Stewart, J. J. P. Development and use of quantum mechanical molecular models. 76. AM1: a new general purpose quantum mechanical molecular model. J. Am. Chem. Soc. 107, 3902-3909 (1985).

34 Ueda, M., Mano, M., Mori, H. \& Ito, H. Polymerization of $\alpha$-methyleneindane: a cyclic analog of $\alpha$-methylstyrene. J. Polym. Sci., Part A: Polym. Chem. 29, 1779-1787 (1991).

35 Ueda, M., Takahashi, M., Suzuki, T., Imai, Y. \& Pittman, C. U. Jr. Polymerization of $\alpha-$ methylene-N-methylpyrrolidone. J.Polym. Sci., Polym. Chem. Ed. 20, 1139-1149 (1983).

36 Ueda, M., Mori, H. \& Ito, H. Radical polymerization of $N$-phenyl- $\alpha$-methylene- $\beta$ lactam. J. Polym. Sci., Part A: Polym. Chem. 28, 2597-2607 (1990).

37 Suenaga, J., Sutherlin, D. M. \& Stille, J. K. Polymerization of (RS)- and (R)- $\alpha$ methylene- $\gamma$-methyl- $\gamma$-butyrolactone. Macromolecules 27, 2913-2916 (1984).

38 Sheikh, Md.R.K., Imae, I., Tharanikkarusu, K., LeStrat, V. M.- J. \& Kawakami, Y. Silacyclobutanes as 'Carbanion Pump' in anionic polymerization I. Anionic polymerization of styrene by potassium $t$-butoxide in the presence of silacyclobutanes. Polym. J. 32, 527-530 (2000).

39 Zundel, T., Baran, J., Mazureki, M., Wang, J.- S., Jerome, R. \& Teyssie, P. Climbing back up the nucleophilic reactivity scale. Use of cyclosila derivatives as reactivity boosters in anionic polymerization. Macromolecules $\mathbf{3 1}, \mathbf{2 7 2 4 - 2 7 3 0}$ (1998).

40 Matsumoto, A., Ishizu, Y. \& Yokoi, K. Solid-state photopolymerization of octadecyl sorbate to yield an alternating copolymer with oxygen. Macromol. Chem. Phys. 199, 2511-2516 (1998). 
41 Matsumoto, A. \& Odani, T. Topochemical polymerization of 1,3-diene monomers and features of polymer crystals as organic intercalation materials. Macromol. Rapid Commun. 22, 1195-1215 (2001).

42 Schmidt, G. M. J. Photodimerization in the solid state. Pure Appl. Chem. 27, 647-678 (1971).

43 Wegner, G. Solid-state polymerization mechanisms. Pure Appl. Chem. 49, 443-454 (1977).

44 Baessler, H. Photopolymerization of diacetylenes. Adv. Polym. Sci. 63, 1-48 (1984).

45 Enkelmann, V. Structural aspects of the topochemical polymerization of diacetylenes. Adv. Polym. Sci. 63, 91-136 (1984).

46 Tieke, B. Polymerization of butadiene and butadiyne (Diacetylene) derivatives in layer structures. Adv. Polym. Sci. 71, 79-151 (1985).

47 Hasegawa, M. Photodimerization and photopolymerization of diolefin crystals. Adv. Phys. Org. Chem. 30, 117-171 (1995).

48 Farina, M. Inclusion Compounds (eds. Atwood, J. L., Davis, J. D. E., MacNicol, D. D.) Vol. 3, p 297, (Academic Press, London, 1984) and references therein.

49 White, D. M. Stereospecific polymerization in urea canal complexes. J. Am. Chem. Soc. 82, 5678-5685 (1960).

50 Minagawa, M., Yamada, H., Yamaguchi, K. \& Yoshii, F. Gamma-ray iirradiation canal polymerization conditions ensuring highly stereoregular (>80\%) polyacrylonitrile. Macromolecules 25, 503-510 (1992).

51 Allcock, H. R., Ferrar, W. T. \& Levin, M. L. Polymerization in clathrate tunnel systems: stereocontrolled polymerization of unsaturated monomers in crystals of Tris(o-phenylenedioxy)cyclotriphosphazene. Macromolecules 15, 697-703 (1982).

52 Allcock, H. R., Silverberg, E. N., Dudley, G. K. \& Pucher, S. R. Inclusion polymerization within a Tris(2,3-naphthylenedioxy)cyclotriphosphazene Clathrate. Macromolecules 27, 7550-7555 (1994).

53 Zhang, X. \& Hogen-Esch, T. E. Synthesis and living anionic polymerization of 9,9dimethyl-2-vinylfluorene. Macromolecules 33, 9176-9178 (2000).

54 Koch, W. \& Holthausen, M. C. A Chemist's Guide to Density Functional Theory p 197-216 (Wiley-VCH, New York, 2000).

55 Bouman, T. D. \& Hansen, A. E. Iterative LORG calculations of nuclear magnetic shieldings. ${ }^{13} \mathrm{C}$ Shielding tensors in 2-norbornenone. Chem. Phys. Lett. 149, 510 (1988).

56 Becke, A. D. Density-functional exchange-energy approximation with correct asymptotic behavior. Phys. Rev. A 38, 3098-3100 (1988).

57 Lee, C., Yang, W. \& Parr, R. G. Development of the Colle-Salvetti correlation-energy formula into a functional of the electron density. Phys. Rev., B 37, 785-789 (1988).

58 Sekine, Y., Brown, M. \& Boekelheide, V. [2.2.2.2.2.2] $(1,2,3,4,5,6)$ Cyclophane: superphane. J. Am. Chem. Soc. 101, 3126-3127 (1979).

59 Allinger, N. L., Yuh, Y. H. \& Lii, J. H. Molecular mechanics. The MM3 Force Field for hydrocarbons. 1. J. Am. Chem. Soc. 111, 8551 (1989).

60 Halgren, T. A. MMFF VII. Characterization of MMFF94, MMFF94s, and other sidely available force fields for conformational energies and for intermolecular-interaction energies and geometries. J. Comput. Chem. 20, 730-748 (1999).

61 Sun, H. COMPASS: an ab initio force-field optimized for condensed-phase applications-overview with details on alkane and benzene compounds. J. Phys. Chem. 102, 7338-7364 (1998).

62 Mohamadi, F., Richards, N. G. J., Guida, W. C., Liskamp, R., Lipton, M., Caufield, C., Chang, G., Hendrickson, T. \& Still, W. C. Macromodel—an integrated software system for modeling organic and bioorganic molecules using molecular mechanics. J. Comput. Chem. 11, 440-467 (1990).

63 Berendsen, H. J. C., Postma, J. P. M., van Gunsteren, W. F., DiNola, A. \& Haak, J. R. Molecular dynamics with coupling to an external bath. J. Chem. Phys. 81, 3684-3690 (1984).

64 Fletcher, R. \& Reeves, C. M. Function minimization by conjugate gradients. Comput. J. 7, 149-154 (1964).

65 Tinoco, I. Hypochromism in polynucleotides. J. Am. Chem. Soc. 82, 4785-4790 (1960).

66 Rohdes, W. Hypochromism and other spectral properties of helical polynucleotides. J. Am. Chem. Soc. 83, 3609-3617 (1961).

67 Ellis, J. R. in Handbook of Conducting Polymers (ed. Skotheim, T.A.) Vol. 1, Chapter 13 (Marcel Dekker, New York, 1986).

68 Houk, K. N., Lee, P. S. \& Nendel, M. Polyacene and Cyclacene geometries and electronic structures: bond equalization, vanishing band gaps, and triplet ground states contrast with polyacetylene. J. Org. Chem. 66, 5517-5521 (2001).

69 Horrocks, D. L. \& Brown, W. G. Solution fluorescence spectrum of highly purified fluorene. Chem. Phys. Lett. 5, 117-119 (1970).

70 Matsuda, M. \& Watanabe, A. in Recent Advances in Anionic Polymerization (eds. Hogen-Esch, T. E., Smid, J.) p 73 (Elsevier, New York, 1987).

71 Hirayama, F. Intramolecular excimer formation. I. Diphenyl and triphenyl alkanes. J. Chem. Phys. 42, 3163-3171 (1965).

72 Strohriegl, P. \& Grazulevicius, J. V. in Handbook of Organic Conductive Molecules and Polymers (ed. Nalwa, H. S.) Vol. 1, Chapter 11 (Wiley, New York, 1997).

73 Pearson, J. M. \& Stolka, M. Poly(N-vinylcarbazole) Chapter 4 (Gordon and Breach, New York, 1981).

74 Ellis, J. R. in Handbook of Conducting Polymers (ed. Skotheim, T. A.), Vol. 1, Chapter 13 (Marcel Dekker, New York, 1986).

75 Borsenberger, P. M. \& Weiss, D. S. Organic Photoreceptor Systems for Imaging Systems (Marcel Dekker, New York, 1993).

76 Shirota, Y. Organic materials for electronic and optoelectronic devices. J. Mater. Chem. 10, 1-25 (2000).

77 Strohriegl, P. \& Grazulevicius, J. V. Charge-transporting molecular glasses. Adv. Mater. 14, 1439-1452 (2002).
78 Gill, W. D. Drift mobilities in amorphous charge-transfer complexes of trinitrofluorenone and poly- $n$-vinylcarbazole. J. Appl. Phys. 43, 5033-5040 (1972).

79 Hoofman, R.J.M.O., de Haas, M. P., Siebbeles, L. D. A. \& Warman, J. M. Highly mobile electrons and holes on isolated chains of the semiconducting polymer poly(phenylene vinylene). Nature 392, 54 (1998).

80 Grozema, F. C., Siebbeles, L. D. A., Warman, J. M., Seki, S., Tagawa, S. \& Scherf, U. Hole conduction along molecular wires: $\sigma$-bonded silicon versus $\pi$-bond-conjugated carbon. Adv. Mater. 14, 228-231 (2002).

81 Grozema, F. C., Hoofman, R.J.O.M., Candeias, L. P., de Haas, M. P., Warman, J. M. \& Siebbeles, L. D. A. The formation and recombination kinetics of positively charged Poly(phenylene vinylene) chains in pulse-irradiated dilute solutions. J. Phys. Chem. A 107, 5976-5986 (2003).

82 Forero, S., Nguyen, P. H., Brütting, W. \& Schwoerer, M. Charge carrier transport in Poly( $p$-phenylenevinylene) light-emitting devices. Phys. Chem. Chem. Phys. 1, 1769-1776 (1999).

83 Kepler, R. G., Zeigler, J. M. \& Kurtz, S. R. Photocarrier generation and transport in $\sigma$-bonded polysilanes. Phys. Rev. B 35, 2818-2822 (1987).

84 Yokoyama, M., Akiyama, K., Yamamori, N., Mikara, H. \& Kusabayashi, S. Hole drift mobility in dimer model compounds of $\operatorname{Poly}(\mathrm{N}$-vinylcarbazole $)$ dispersed in a polymer binder. Polym. J. 17, 545-548 (1985).

85 Fujino, M., Mikawa, H. \& Yokoyama, M. Charge carrier transport in Poly $(\mathrm{N}$-vinylcarbazole). Photogr. Sci. Eng. 26, 84-87 (1982).

86 Murphy, C. J., Arkin, M. R., Jenkins, Y., Ghatlia, N. D., Bossman, S. H., Turro, N. J. \& Barton, J. K. Long-range photoinduced electron transfer through a DNA helix. Science 262, 1025-1029 (1993).

87 Okahata, Y., Kobayashi, T., Tanaka, K. \& Shimomura, M. Anisotropic electric conductivity in an aligned DNA cast film. J. Am. Chem. Soc. 120, 6165-6166 (1998).

88 Fink, H.- W. \& Schönenberger, C. Electrical conduction through DNA molecules. Nature 398, 407 (1999).

89 Porath, D., Bezryadin, A., de Vries, S. \& Dekker, C. Direct measurement of electrical transport through DNA molecules. Nature 403, 635-638 (2000).

90 Braun, E., Eichen, Y., Sivan, U. \& Ben-Yoseph, C. DNA-templated assembly and electrode attachment of a conducting silver wire. Nature 391, 775-778 (1998).

91 Debije, M. G., Milano, M. T. \& Benhard, W. A. DNA responds to ionizing radiation as an insulator, not as a 'molecular wire'. Angew. Chem., Int. Ed. 38, 2752-2756 (1999).

92 Maiya, B. G. \& Ramasarma, T. DNA, a molecular wire or not-the debate continues. Curr. Sci. 80, 1523-1530 (2001).

93 Nakano, T. \& Yade, T. Charge delocalization over stacked $\pi$-electron systems. Chem. Lett. 37, 258-259 (2008).

94 Coropceanu, V., Nakano, T., Gruhn, N. E., Kwon, O., Yade, T., Katsukawa, K.-i. \& Bredas, J.- L. Probing charge transport in $\pi$-stacked fluorene-based systems. J. Phys. Chem. B 110, 9482-9487 (2006).

95 Okamoto, Y., Suzuki, K., Ohta, K., Hatada, K. \& Yuki, H. Optically active poly(triphenylmethyl methacrylate) with one-handed helical conformation. J. Am. Chem. Soc. 101, 4763-4765 (1979).

96 Nakano, T., Okamoto, Y. \& Hatada, K. Asymmetric polymerization of triphenylmethyl methacrylate leading to a one-handed helical polymer: mechanism of polymerization. J. Am. Chem. Soc. 114, 1318-1329 (1992).

97 Green, M. M., Park, J.- W., Sato, T., Teramoto, A., Lifson, S., Selinger, R. L. B. \& Selinger, J. V. The macromolecular route to chiral amplification. Angew. Chem. Int. Ed. 38, 3138-3154 (1999).

98 Mislow, K. \& Bickart, P. An epistemological note on chirality. Isr. J. Chem. 15, 1-6 (1977).

99 Nakano, T. \& Okamoto, Y. Synthetic helical polymers: conformation and function. Chem. Rev. 101, 4013-4038 (2001).

100 Okamoto, Y. \& Nakano, T. Asymmetric polymerization. Chem. Rev. 94, 349-372 (1994).

101 Hill, D. J., Mio, M. J., Prince, R. B., Hughes, T. S. \& Moore, J. S. A field guide to foldamers. Chem. Rev. 101, 3893-4012 (2001).

102 Cornelissen, J.J.L.M., Rowan, A. E., Nolte, R. J. M. \& Sommerdijk, N.A.J.M. Chiral architectures from macromolecular building blocks. Chem. Rev. 101, 4039-4070 (2001).

103 Nakano, T. \& Okamoto, Y. Asymmetric polymerization of methacrylates. Macromol. Rapid. Commun. 21, 603-612 (2000).

104 Rowan, A. E. \& Nolte, R. J. M. Helical molecular programming. Angew. Chem. Int. Ed. 37, 63-68 (1998).

105 Gelman, S. H. Foldamers: a manifesto. Acc. Chem. Res. 31, 173-180 (1998).

106 Natta, G., Pino, P., Corradini, P., Danusso, F., Mantica, E., Nazzanti, G. \& Moraglio, G. Crystalline high polymers of $\alpha$-ofeins. J. Am. Chem. Soc. 77, 1708-1710 (1955).

107 Pino, P. \& Lorenzi, G. P. Optically active vinyl polymers. II. The optical activity of isotactic and block polymers of optically active $\alpha$-olefins in dilute hydrocarbon solution. J. Am. Chem. Soc. 82, 4745-4747 (1960).

108 Pino, P., Lorenzi, G. P. \& Lardicci, L. Optically active vinyl polymers. I. Preparation of isotactic polymers of optically active $\alpha$-olefins. Chim. e Ind. (Milan) 42, 712-721 (1960).

109 Yashima, E. \& Maeda, K. Chirality-responsive helical polymers. Macromolecules 41, 3-12 (2008).

110 Yashima, E., Maeda, K. \& Furusho, Y. Single- and double-stranded helical polymers: synthesis, structures, and functions. Acc. Chem. Res. 41, 1166-1180 (2008).

111 Yashima, E., Maeda, K., lida, H., Furusho, Y. \& Nagai, K. Helical polymers: synthesis, structures, and functions. Chem. Rev. 109, 6102-6211 (2009). 


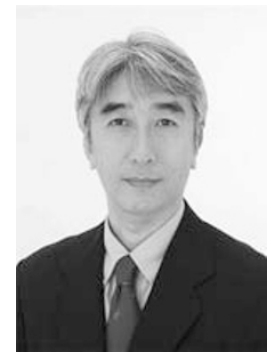

Tamaki NAKANO received his BS (1986), MS (1988) and PhD (1991) degrees from Osaka University in the group of Professor Yoshio Okamoto. In 1990, he joined Nagoya University, working with Professor Yoshio Okamoto as Assistant Professor and was promoted to Associate Professor in 1998. He moved to the Nara Institute of Science and Technology (NAIST) as Associate Professor in 1999 and joined Hokkaido University in 2006 as a full Professor. He was a visiting scientist at Cornell University (1993-1994) working with Professor Dotsevi Y Sogah and PRESTO Project (JST) researcher (2000-2003). He received the Award for the Outstanding Paper published in the Polymer Journal from SPSJ in 1995 and the Award of the Society of Polymer Science, Japan in 2009. His current research interests are in the design and synthesis of $\pi$-electronic polymers and chiral polymers having controlled shapes and novel properties. 